\title{
Continuidad y cambios en una vieja democracia de partidos Uruguay (1910-2010)
}

\begin{tabular}{c}
\hline \hline Jorge Lanzaro \\
Instituto de Ciencia Política \\
Universidad de la República (Uruguay) \\
\hline \hline
\end{tabular}

\begin{abstract}
Resumo: Este artículo revisita la vieja democracia de partidos uruguaya - la más antigua y una de las pocas de América Latina . retomando críticamente aportes señeros y propuestas propias, para señalar cambios y continuidades en el correr de cien años. Tratando de no caer en el excepcionalismo, el texto hilvana referencias comparativas, que encuadran la originalidad del caso uruguayo y permiten resaltar el potencial que su análisis tiene para la Política Comparada. La primera parte repasa el modelo genético y los rasgos típicos del régimen, que explican sus ventajas comparativas: los factores originarios, la matriz poliárquica, el presidencialismo pluralista, una democracia consociational sui generis, hecha de partidos políticos y no de clivajes sociales. La segunda parte aborda la gran transformación que sigue a la transición democrática de los 1980, mostrando un sistema de partidos que cambia sin desarticularse, recomponiendo su estructura plural y competitiva. El texto evoca la transición liberal de los 1990 y la reforma constitucional de 1996, el fin del bipartidismo tradicional, el perfil de predominante que alcanza el Frente Amplio y su debut con un gobierno de tipo social democrático, comparable a las social democracias "tardías" de Europa Meridional. En todos estos lances, la centenaria democracia de partidos uruguaya - que en su momento no pudo evitar la dictadura 1973-1984 - vuelve a hacer la diferencia y al cabo de un proceso histórico largo y gradual, termina acuñando una nueva norma política.
\end{abstract}

Palavras-chave: Uruguay; democracia de partidos; sistema de partidos; historia política

\begin{abstract}
This article "revisits" the old Uruguayan party democracy - the eldest and one of the few in Latin America- reviewing wellknown contributions as well as my own proposals, to point out persistence and changes during the last century. Trying to avoid "exceptionalism", the text interweaves comparative references, which provide a framework for the originality of the Uruguayan case and make it possible to further highlight its potential for Comparative Politics. The first part reviews the genetic model and the typical features of the Uruguayan regime, explaining its comparative advantages: the historical background and the polyarchy origins, pluralist presidentialism, and a sui generis consociational democracy, made up by political parties and not of social cleavages. The second part deals with the great transformation following the democratic transition of the 1980, arising from the changes in the party system, which do not prompt its breakdown but instead reshape its plural and competitive structure. This section reviews the liberal transition of the 1990 and the 1996 constitutional reform, the decline of the traditional two-party system and the Frente Amplio's development into a predominant party, including its debut with a social democratic government, which echoes the "late" social democracies in Southern Europe. Through all this, the renewed Uruguayan party democracy . which at the time could not avoid the dictatorship 1973-1984 - continues to make a difference and at the end of a long and gradual process, forges a new political norm.
\end{abstract}

Keywords: Uruguay; party democracy; party system; political history 
OPINIÃO PÚBLICA, Campinas, vol. 19, n², novembro, 2013, p. 235-269

\section{Introducción ${ }^{1}$}

La democracia uruguaya ha sido históricamente una democracia de partidos. Como tal, constituye un caso bastante inusual en América Latina. Es una de las democracias de partidos más antiguas del mundo y una de las más viejas de la región, ya que ha podido persistir desde comienzos del siglo XX, con dos interrupciones autoritarias y a través de una sucesión de cambios significativos.

La expresión democracia de partidos (Parteiendemokratie, Party Democracy) es la más adecuada para definir el régimen uruguayo, se emparenta con la idea de "república de partidos" o con la noción de party government y comporta un juicio positivo: una valoración acorde con las posturas que consideran a los partidos como actores imprescindibles de la democracia moderna, las cuales se abren camino desde principios del siglo XX y más nítidamente, a partir de los años 1940, después de las experiencias autoritarias precedentes ${ }^{2}$.

El término "partidocracia", que también destaca la centralidad de los partidos en la civilización uruguaya (Romeo Pérez, 1984; Caetano, Rilla \& Pérez, 1988), tiene en política comparada una connotación crítica y hasta peyorativa. En esta tecla, la partidocracia se concibe como "una indebida dominación de las partes sobre el todo" (BOBBIO, 1991); una presencia "intrusiva" en la política y en la sociedad, o incluso como una "tiranía de los partidos", que distorsiona las instituciones formales de gobierno (SARTORI, 1994); resultando "particularmente perjudicial" para la democracia, cuando aparece en un régimen presidencial (COPPEDGE, 1994). El ejemplo más conocido de este enfoque negativo lo ofrece el empleo del término "partitocrazia", que se hizo común en Italia desde fines de los años 1950, durante la vigencia del sistema de partidos constituido en la segunda postguerra, en una denominación marcada por sentimientos de "indictment and alarm" (LAPALOMBARA, 1987). En cambio, para caracterizar el régimen italiano de esa época con una valoración positiva, se ha usado el término "reppublica dei partit”" (SCOPPOLA, 1991), que remonta la concepción clásica de la república de ciudadanos y se identifica de hecho con la noción más moderna de la democracia de partidos. En América Latina se ha hablado de "partyarchy" respecto a Colombia, a Honduras y especialmente a Venezuela, mientras duró el

\footnotetext{
1 Una versión más breve de este trabajo "Persistence and Change in an Old Party Democracy", se publicó en Lawson \& Lanzaro (2010).

2 Como es sabido, para las concepciones liberales primarias y en las ediciones constitucionales de los siglos XVIII y XIX, los partidos eran intromisiones indeseables que las normativas jurídicas debían eventualmente proscribir. Con el advenimiento del sufragio universal y de la política de masas moderna, desde el tránsito al siglo XX. los partidos pasan a ser vistos como agentes benéficos y hasta imprescindibles, para organizar el sistema político y poner en obra la democracia. Esta perspectiva se refuerza al influjo de las crisis políticas de la primera mitad del siglo XX y visto que varios de los regímenes autoritarios de entonces, en particular los fascismos, renegaban de la democracia representativa y proponían organizaciones de masas de otro tipo. A esas lecciones negativas se sumaron las enseñanzas positivas de los partidos democráticos que reconquistan legitimidad en las transiciones que marcan la salida de las dictaduras. Así pues, a partir de los años 1940, las posturas se revierten y llega incluso a prosperar la idea de que "la democracia moderna es impensable si no es en términos de partidos" (SCHATTSCHNEIDER, 1942). Algo que Kelsen ya había proclamado en los años 1920, en tiempos de la República de Weimar: "es ilusorio o hipócrita sostener que la democracia es posible sin partidos políticos" . "la democracia es necesaria e inevitablemente el gobierno de los partidos (Parteienstaat), (citado por Manin, 1997, p. 211). Con una proyección que trasciende las comarcas europeas, el clásico manual de Maurice Duverger (1951) se convierte en un referente emblemático de la valoración positiva de los partidos. En la misma línea se ubica Robertson (1976): "To talk today, about democracy, is to talk about a system of competing political parties", así como el trabajo señero de John Aldrich (Why Parties?, 1995). Para un análisis de las posiciones con respecto a los partidos ver el repaso erudito de Susan Stokes (1999) y el texto de Hans Daalder (2002), quien propone una excelente sistematización y una certera crítica anti-crítica. En los debates contemporáneos de Teoría Política, Nadia Urbinati vuelve a hacer una defensa sólida de la democracia representativa y del papel fundamental que tienen en ella los partidos (URBINATI, 2006). En América Latina, como en otras regiones, se advierte asimismo que las democracias con sistemas de partidos consistentes, tienden a ser más estables y duraderas, aun con interrupciones autoritarias (DRAKE, 2009; HARTLYN \& VALENZUELA, 1998). Por cierto, a pesar de este reconocimiento, vuelta a vuelta y particularmente en las coyunturas históricas de cambio, suelen medrar las ideologías antipartido, de izquierda y de derecha, en un arco que va desde el "democratismo ingenuo" a las tendencias autoritarias.
} 
LANZARO, J. Continuidad y cambios en una vieja democracia de partidos...

sistema de partidos formado a partir del Pacto de Punto Fijo, desde 1958 hasta la crisis terminal de fines de los 1990 (COPpEDGE, 1994). Recientemente, también el sistema chileno ha sido analizado en términos críticos como "partidocracia" (SIAVELIS, 2009).

El régimen uruguayo se basa en un sistema de partidos plural y competitivo, de larga vida, que alcanza un alto grado de institucionalización. El sistema de partidos nació con el país mismo - en la primera mitad del siglo XIX - y se ubica entre los más longevos del mundo (SoTELO, 1999). Inicialmente fue un sistema bipartidista, integrado por el Partido Colorado ("colorados") y el Partido Nacional ("blancos"), que dominaron la arena política desde las guerras civiles originarias hasta las últimas décadas del siglo XX. Los dos conjuntos se constituyeron desde un principio como partidos populares catch-all y tuvieron una fuerte implantación ciudadana, así como una densa red de linkages con los gremios empresariales y las más diversas organizaciones de la sociedad civil, desde los clubes de fútbol y los agrupamientos de emigrantes, a las mutualistas o las asociaciones de funcionarios públicos (LANZARO, 1986; GONZÁleZ, 1993).

A su sombra y más de una vez como compañeros de ruta, convivían los "partidos de ideas" (Partido Socialista, Unión Cívica, Partido Comunista), fundados precisamente cuando se asienta la democracia electoral, a partir del año clave de 1910. Al comienzo y por muchas décadas, fueron partidos de tipo ideológico, con escasa convocatoria electoral, que obraban como núcleos testimoniales y partidos "picana" vis à vis los sectores tradicionales. Ganaron cierta importancia política en la transición democrática que se abre hacia mediados de los años 1930 y especialmente desde los 1940, al convertirse en "partidos de apoyo" del segundo batllismo, en un cuadro de alianzas o coaliciones "implícitas". Intervinieron entonces en la articulación de algunas propuestas estratégicas, como es el caso, tan relevante, de la norma de 1943 que estableció, en el mismo cuerpo legal, los primeros consejos de salarios y el régimen de asignaciones familiares. La participación consecutiva en el segmento de representación corporativa, en los propios consejos de salarios y en la administración tripartita de la seguridad social, proporciona fuentes de poder - subordinadas, pero significativas - que conquistaron sobre todo los comunistas y los socialistas, gracias a sus bases en el movimiento sindical (LANZARO, 1986).

Los dos partidos mayores sobrellevaron varios ciclos de crisis y fueron los protagonistas principales en sucesivas fases de cambio, en una secuencia histórica a lo largo de la cual ambas colectividades y el sistema en su conjunto tuvieron diversas configuraciones. Sin embargo, a diferencia de lo que ocurrió durante mucho tiempo, el bipartidismo tradicional no salió ileso de la última coyuntura crítica. En el correr de los años 1960 y en el marco de la crisis política que terminó llevándonos a la dictadura, los viejos partidos de ideas pusieron en obra nuevas estrategias y en coalición con sectores provenientes de tiendas blancas y coloradas, formaron el Frente Amplio (1971), que se constituyó como congregación unitaria de la izquierda y logró abrir una brecha en el bipartidismo.

A partir de la transición democrática que se inició en 1980, el sistema de partidos recuperó consistencia y centralidad, pasando por un segundo ciclo de cambios que dio lugar a una transformación formidable: los partidos tradicionales perdieron terreno, mientras que el Frente Amplio confirmó su tercería y logró un crecimiento sostenido. En 1999 llegó a convertirse en el partido más grande del 
OPINIÃO PÚBLICA, Campinas, vol. 19, n², novembro, 2013, p. 235-269

espectro uruguayo y en 2004 conquistó finalmente el gobierno, reteniéndolo por un segundo período en 2009.

Se consolidó así un realineamiento gradual, duradero y de gran envergadura. La izquierda logró adquirir una posición mayoritaria y el bloque de los partidos tradicionales fue bajando paso a paso su caudal (Tabla 1). En las elecciones de 1984, que franquearon el regreso a la democracia, los blancos y los colorados todavía recababan entre ambos el $81 \%$ de los votos; diez años más tarde, en las elecciones de 2004 , juntaron el $46 \%$ de los votos (porcentaje que se repite en 2009). El Partido Colorado - que gobernó por períodos que en conjunto suman más de cien años - quedó reducido en la elección de 2004 a un magro $10 \%$, remontando al $17 \%$ en $2009^{3}$. Por ende, el sistema de partidos persiste, en una clave de continuidad y cambio. Todos sus integrantes siguen en carrera, aunque ha habido una mutación estructural, que modifica el lugar que ocupan y las funciones que cumplen en el sistema.

Tabla 1

Apoyo Electoral por Bloques 1971-2009

Votos Válidos (\%)

\begin{tabular}{|c|c|c|}
\hline & $\begin{array}{c}\text { Partido Colorado + Partido } \\
\text { Nacional }\end{array}$ & Frente Amplio \\
\hline 1971 & 81 & 21 \\
\hline 1984 & 76 & 21 \\
\hline 1989 & 69 & 30 \\
\hline 1994 & 63 & 40 \\
\hline 1999 & 55 & 52 \\
\hline 2004 & 46 & 48 \\
\hline 2009 & 46 & \\
\hline Fuente: Banco de Datos FCS - Área Política y Relaciones Internacionales: http://www.edu.uy/pri.
\end{tabular}

Este proceso confirma la idea de que una institucionalización fuerte no es sólo la que prevalece en situaciones estáticas que implican eventualmente el freezing del sistema de partidos (LIPSET \& ROKKAN, 1967), sino precisamente la que transita con cierta entereza por una mutación de gran calado, poniendo a prueba la capacidad de adaptación y de control político de los partidos y de los sistemas de partidos, ante cambios significativos que alteran las estructuras de competencia y las relaciones con ante cambios significativos que alteran las estructuras de competencia y las relaciones con la ciudadanía (MAIR, 1997)4.

3 Salvas las distancias, la transformación del sistema de partidos uruguayo podría compararse con la que experimentó Inglaterra durante las primeras décadas del siglo XX, particularmente después del establecimiento del sufragio universal en 1918: una fase durante la cual el Partido Laborista fue creciendo, hasta devenir el contrincante principal del Partido Conservador, mientras que el Partido Liberal pasó a una tercería de caudal bajo, pero se ha mantenido en competencia (con una gran pendiente desde los años 1930 hasta los 1970, que luego consiguen remontar).

${ }_{4}^{4}$ Mutaciones significativas en el modelo de desarrollo, la forma del Estado, los medios de comunicación, la estructura política y el propio sistema de partidos, que suelen ir acompañadas de cambios en el gobierno, el régimen electoral, la organización de los partidos y sus élites, sus modalidades de reproducción y sus recursos de poder, el tipo de linkages y las pautas de legitimación ... La coyuntura crítica por la que ha atravesado Uruguay y el conjunto de los países de América Latina en las últimas décadas, es 
LANZARO, J. Continuidad y cambios en una vieja democracia de partidos...

En este sentido, valen las observaciones de Alfredo M. Errandonea (padre), sosteniendo - en referencia al caso uruguayo - que las mutaciones electorales en democracias pluralistas con ejercicios efectivos de sufragio universal, pueden ser consideradas como un indicador de estabilidad política, en la medida que no desbordan las estructuras institucionales y los encuadres de partido (ERRANDONEA, 1972).

La democracia uruguaya ha sido en gran medida obra de los partidos y está ligada a las vicisitudes del sistema de partidos, sus períodos de prosperidad y sus debilidades, sus crisis y sus cambios. Esta circunstancia modela nuestro régimen democrático, lo ubica entre los más estables y duraderos de América Latina - aun contando las interrupciones sufridas en el siglo XX (DRAKE, 2009; HARTLYN \& VALENZUELA, 1998) - y tiene las consecuencias que se asocian usualmente con la política de partidos plural y competitiva.

Este rasgo fundamental tiende a moderar la concentración de poderes y propone mejores equilibrios en la distribución de la autoridad pública. En una geometría "madisoniana", para que los checks and balances y los cursos del pluralismo político resulten efectivos, la separación de poderes debe ser apuntalada por dispositivos institucionales apropiados, con diseños orgánicos, reglas e incentivos conducentes, así como recursos funcionales suficientes (MADISON, 1788; CARROLL \& SHUGART, 2007). Pero además de buenos diseños, se requiere de un sistema de partidos plural y competitivo, cuyas energías aniden en las instituciones y animen efectivamente su funcionamiento, regando en forma adecuada la vida democrática. Esto delinea una diferencia decisiva entre los regímenes políticos y en el ámbito particular de América Latina genera una distinción básica entre los presidencialismos con partidos y los presidencialismos sin partidos (LANZARO, 2011b) ${ }^{5}$.

Tal distinción vale en términos históricos a largo plazo y en particular para los dos grandes ciclos por los que ha atravesado América Latina en las últimas décadas: para catalogar los gobiernos que llevaron adelante las reformas pro-mercado, de signo neo-liberal (especialmente en la década de los 1990) y también los gobiernos de izquierda que se multiplican a comienzos del siglo XXI (LANZARO, 2006; 2008; 2011a).

La competencia efectiva y el balance de poderes son los factores más relevantes para el surgimiento y la afirmación de estructuras democráticas poliárquicas en los procesos de fundación de los sistemas políticos (BARRINGTON MOORE, 1966; DAHL, 1971). En sus análisis sobre la viabilidad y la estabilidad a largo plazo de las democracias, Robert Dahl identifica las distintas trayectorias que modelan las transiciones históricas originarias y concluye que la ruta competitiva ("the way of competitive oligarchy") es la más propicia para el establecimiento de un régimen de poliarquía duradero (DAHL, 1971, p. 36). El caso de Uruguay es en este sentido ejemplar.

Considero que este principio competitivo, en obra para la "acumulación primitiva", es también válido para las coyunturas críticas sucesivas, que constituyen otras tantas estructuras de oportunidad, en

en este sentido un laboratorio formidable, en el que tales fenómenos se encadenan, de modo que los partidos y los sistemas de partidos atraviesan por una fase de "darwinismo político" (COPPEDGE, 2001; LANZARO, 2007a).

5 Como enseña Duverger (1951): "Le degré de séparation des pouvoirs dépend beaucoup plus du système des partis que des dispositions prévues par les Constitutions. ... La séparation réelle des pouvoirs est donc le résultat d’une combinaison entre le système des partis et le cadre constitutionnel". En el mismo sentido va la sentencia de Hofstadter: "It is necessary to have more than 'a scheme of checks and balances within the government'... So in a republic 'parties take the place of the old system of balances and checks'" (HOFSTADTER, 1969, retomando ideas expuestas por Frederick Grimke, en The Nature and Tendency of Free Institutions, 1848) 
las que puede haber, una y otra vez, alternativas democráticas y posibilidades de construcción pluralista. Ese basamento pluralista delinea un patrón decisorio marcado por los equilibrios entre mayorías y minorías, con metabolismos que tienden a generar eventualmente consensos más extensos o al menos, disensos más limitados. Los productos políticos suelen ser por ende gradualistas y moderados, mediante "ajustes incremementales" y por caminos sinuosos (en lógicas de "muddling through"), resultando por eso mismo más estables y confirmando que las democracias "no se mueven a grandes saltos" (LINDBLOM, 1959).

Esta métrica parece dar algo de razón a los devotos de la ideología del "bloqueo", que hoy como ayer, menudean a izquierda y derecha. Sin embargo, más que al "conservadurismo de la democracia" (HUNTINGTON, 1968), ese canon responde a "la inteligencia de la democracia" (LINDBLOM, 1965) y remite a la manera como se tramitan por lo general los cambios en los regímenes pluralistas.

Además, la política de partidos competitiva abre posibilidades para la redistribución de poderes y de bienes en la economía y en la sociedad - mediante intervenciones reguladoras y prestaciones públicas - a través de compromisos que atienden a los requerimientos de los sectores populares y de las clases medias, pero al mismo tiempo contemplan los intereses y los riesgos de "escape" de las clases altas. Por otra parte, las reacciones conservadoras y los empujes liberales, que generan movimientos pendulares y focos de polarización, pueden pasar por un tamiz de vetos y políticas de ajuste, que también los hacen relativamente moderados.

Contrariamente a lo que surge de algunos enfoques teóricos, es el pluralismo en la política el que permite que florezca el pluralismo en la sociedad. Y no al revés. El pluralismo es con frecuencia analizado a partir de las configuraciones de la sociedad civil, teniendo en cuenta el número, la pluralidad y la autonomía de los sujetos que la componen: las "desigualdades dispersas" o un supuesto equilibrio de los actores sociales y de las organizaciones colectivas, como titulares de intereses y poderes que compiten entre sí y se relacionan con la autoridad central del gobierno, contraponiéndose a ella y articulando sus demandas ${ }^{6}$. Desde una perspectiva que reconoce la centralidad y la autonomía de la política, cabe sostener en cambio que la competencia efectiva y el balance de poderes entre los partidos deja mejores márgenes para el pluralismo social, autorizando que el "mundo de las asociaciones" y la "política de grupos" resulten realmente animadas por actores colectivos plurales, relativamente autónomos y más enérgicos ${ }^{7}$.

En fin, el hecho de que el sistema de partidos uruguayo haya sido plural y competitivo desde sus orígenes, es la clave de la construcción de un presidencialismo de tipo pluralista, que constituye un caso ejemplar en el campo del presidencialismo latinoamericano (LANZARO, 2001). Sartori (1980) sostuvo

\footnotetext{
${ }^{6}$ Más allá de los avances de Alexis de Tocqueville sobre la "democracia en la sociedad", esta aproximación remite al paradigma americano de la "group politics", que tiene su expresión señera en el trabajo de Bentley (1908) y se abre paso con el aporte decisivo de Truman (1951) y las producciones siguientes. El enfoque alimentó desde entonces la mainstream en este campo y logra una irradiación importante, a medida que se extiende la influencia las ideologías teóricas de origen anglosajón. Esta visión socio-céntrica - de factura sociológica - que empapa los análisis sobre el estado, el sistema político y los partidos, se emparenta con los postulados economicistas del marxismo, generando de hecho un acercamiento, aparentemente paradójico, que liga a dos corpus secularmente enfrentados. Los abordajes del neo-pluralismo y del neo-marxismo, cada uno a su manera, pero con similar convergencia, avanzan en un replanteo algo más "politicista" de las versiones tradicionales del pluralismo y del marxismo.

7 La prueba en contrario puede buscarse sin ir más lejos en México, durante el largo reinado del PRI: con una estructura de presidencialismo "imperial" y un sistema de partido monopólico, que encuadraba a la sociedad y proporcionaba un ordenamiento piramidal, mediante una fuerte compenetración del partido, el estado y las redes corporativas, construida hacia fines de los años 1920 y afianzada con el Cardenismo.
} 
LANZARO, J. Continuidad y cambios en una vieja democracia de partidos...

que en Uruguay había un sistema de partido predominante, dado que el Partido Colorado permaneció durante noventa años en el gobierno, de corrido entre 1868 y $1958^{8}$. Las referencias usuales al Uruguay "batllista" y especialmente los enfoques sobre el carácter fundacional de la obra de Batlle y Ordóñez . como "creador de su tiempo" (VANGER, 1963) - hablan también de una cierta primacía histórica y de la existencia de un sector de punta, por cierto muy influyente. Sin embargo y a pesar de que durante muchas décadas no hubo alternancia, el sistema de partidos nunca dejó de ser plural y competitivo. La oposición ha sido constante y organizada. En varios tramos hubo alianzas y coaliciones de gobierno, de sectores colorados con sectores blancos. Y en general, las resoluciones de gobierno - incluyendo aquellas que hacen época - resultan de una dinámica de competencia efectiva y son producto del mercado político, de la rivalidad de iniciativas y de los vetos - impulsos y frenos - de los ajustes ex ante y los ajustes ex post, el intercambio y la negociación entre partidos y entre fracciones de partido, resultando en un sistema de compromisos, que riega precisamente las prácticas del presidencialismo pluralista.

Debido a que el bipartidismo tradicional moldea la estructura del Estado y el patrón de los procesos decisorios, este régimen tuvo por muchos años las características de una peculiar consociational democracy (LIJPHART, 1969; LANZARO, 1986; 2004). Tales factores políticos fueron asimismo determinantes para delinear el tipo de desarrollo que se despliega por etapas desde principios del siglo XX, el cual instaló un modelo estado-céntrico de trazos específicos e inauguró tempranamente un social welfare "schumpeteriano" que hizo época.

Sin embargo, Uruguay no se salvó de las rupturas autoritarias, que sobrevinieron cada vez que los partidos fallaron en su productividad política, en sus deberes de lealtad y en los flujos de cooperación, cuando la pluralidad de poderes pasó a operar en términos de desagregación y de polarización aguda. El pluralismo es pues la clave de la prosperidad de un tipo de democracia y llegado el caso, un factor de su propia crisis. De hecho, varias coyunturas críticas atravesaron por una secuencia de momentos autoritarios y de momentos democráticos, mediante los cuales se procesan los cambios y surgen nuevos diseños políticos. Es lo que sucedió en el último tercio del siglo XIX, en las fases fundacionales del estado. Ocurrió también en los años 1930, al abrirse un período de reformas que impulsó la segunda expansión del Estado y el desarrollo del mercado interno. Es, en fin, lo que sobrevino a raíz de la crisis política que se despliega desde los 1960, que desembocó en la dictadura más larga y gravosa de la historia del país (1973-1984).

Luego de la transición democrática, iniciada en 1980, se consolidó otra gran transformación del modelo de desarrollo, se abrió un ciclo de reformas del Estado y hubo un cambio mayúsculo en la estructura política: la democracia de partidos recobró su vitalidad y redobló su carácter competitivo, pero el nuevo sistema de partidos y las modalidades de gobierno que vinieron con él, la reforma constitucional de 1996 y el nuevo régimen electoral que ella impuso, alteraron las viejas pautas consociationa/ y rebajaron en cierta medida el pluralismo.

En el cauce de la democracia de partidos restaurada, que pasa en sí misma por una fase de mutación, se impulsó durante los 1990 la transición liberal, mediante reformas pro-mercado del Estado y

8 La opinión de Sartori fue discutida, con distintos argumentos, por González (1993) y por Mieres (1992). En una tesitura similar se ubica Fitzgibbon (1957), emparentando al Partido Colorado con el PRI de México, dado que ambos eran difíciles de desplazar. Almond \& Coleman (1960) consideran estos dos casos como posibles ejemplos de la categoría de "partido dominante no dictatorial", propuesta por George Blanksten. 
de la economía. Debido a la competencia inter e intra partidaria, la transición liberal fue gradualista y más moderada que en los países de la región donde las reformas de mercado se tramitaron sin partidos o sin competencia efectiva.

A comienzos del siglo XXI, cuando se verifica un giro a la izquierda en muchos países de América Latina, Uruguay inaugura un gobierno de tipo social-democrático (2005-2010), del mismo género que los existentes en Brasil y Chile (2000-2010). Una vez más, la marca de fábrica proviene del sistema de partidos, estableciendo una diferencia política básica respecto a otros gobiernos de izquierda de la región y en particular frente a los nuevos populismos (LANZARO, 2008; 2011a-b). Precisamente, Io que distingue a las experiencias de tipo social-democrático es que se llevan adelante por una izquierda institucional, en el marco de un sistema de partidos que, a pesar de sus cambios - mejor dicho, a través de ellos - sigue siendo plural y competitivo.

La llegada del segundo gobierno de la izquierda en 2010 aporta una novedad provechosa que muestra otra vez las potencialidades de la democracia de partidos y el efecto moderador de las gramáticas pluralistas. José Mujica llega a la presidencia gracias a que el Frente Amplio renueva su performance en la elección de 2009 y debido a que él y sus congéneres Tupamaros acomodaron su comportamiento a la política de partidos y a una competencia electoral exigente, dejando de lado el pasado guerrillero, las posturas voluntaristas más desafiantes y el populismo radical. Por añadidura, al comenzar la presidencia, Mujica adopta de motu proprio algunos modales propios de la república de partidos - contra la que se había alzado en los años 1960 - y repone el antiguo expediente de la coparticipación, incorporando a representantes de la oposición en los entes públicos.

A cien años de aquel mojón histórico de 1910, el régimen electoral ha tenido una alteración terminante y vuelve a haber un gobierno mayoritario, compuesto solo por el Frente Amplio. Pero la democracia de partidos muestra su vitalidad y si bien perdió ciertas características matrices, logra recuperar - en otro cuadro - alguna de sus más preciosas tradiciones políticas. En virtud de los rasgos evocados, la trayectoria uruguaya sobresale en la historia y en el paisaje actual de América Latina, donde - después de la saga de regímenes autoritarios - hay democracias sin partidos o sin sistemas de partidos y los regímenes políticos muestran carencias de pluralidad y de competencia efectiva.

Las páginas que siguen proponen una "revisita" de nuestra vieja democracia de partidos, su matriz y su peripecia histórica, retomando aportes señeros y propuestas propias. Se trata de repasar características raigales, continuidades y cambios, sin caer en el "excepcionalismo" y las miradas provincianas, hilvanando referencias comparativas, que sirven para encuadrar de otra manera la originalidad del caso uruguayo y permiten resaltar el potencial teórico que de verdad tiene en la Política Comparada.

\section{Rasgos Matrices de la Democracia Pluralista De las armas a las urnas: "the only game in town"}

Los partidos tradicionales fueron actores decisivos de la construcción del Estado y adquirieron una centralidad considerable, de par con la centralidad que el propio Estado tendrá desde un principio en el Uruguay (BARRÁN \& NAHUM, 1984). Los partidos fueron consolidando esa centralidad - en conjunto por su vitalidad y en la medida en que acudieron a componer un sistema, entre ellos y de cara a los demás actores, en un escenario que era propicio para la construcción de poderes específicamente 
LANZARO, J. Continuidad y cambios en una vieja democracia de partidos...

políticos. A favor de esto obra la debilidad relativa de los poderes de otra naturaleza - oligarquías económicas, fuerzas militares, iglesia católica (REAL DE AZÚA, 1984) - lo que se debe básicamente a la ausencia de sociedad campesina o de una civilización indígena, jerárquica y sedentaria, en modos de producción agrícolas o con enclaves mineros.

Estas circunstancias - que establecen una diferencia genética fundamental en relación a otras patrias latinoamericanas - moldearon el tipo de implantación colonial y luego las características del país, que nace como una "nación nueva". En efecto, Uruguay surge en un territorio relativamente "vacío", de "tierras de ningún provecho" y colonización tardía, con baja densidad demográfica y una fuerza de trabajo móvil - de magro desarrollo cultural y lo que resulta decisivo, sin poderes centralizados fuertes - que era por tanto más libre y difícil de dominar, mostrando una extraordinaria capacidad de resistencia frente a la autoridad y a la subordinación laboral ${ }^{9}$. Estos rasgos están en el origen de las campañas de desplazamiento y exterminio de los indios, así como del patrón de asentamientos que prevaleció en nuestra comarca, del tipo de mestizaje y del modo de asentamiento de las camadas migratorias, dando lugar a esa composición peculiar de "pueblos trasplantados" que retrató Darcy Ribeiro (RIBEIRO, 1969).

De ahí el perfil singular de las estructuras de clase que vendrán y sus magnitudes peculiares de autonomía (LANZARO, 1986). De ahí también, algunos elementos raigales de nuestra cultura cívica, en particular, las tendencias al igualitarismo - anteriores a la democracia - que influyen en los modos de ejercicio de las jerarquías en los diversos ámbitos de la sociedad, en las unidades económicas y en la política. Con todo esto vino una formidable ventaja comparativa: mayores facilidades para construir poderes específicamente políticos, armazones de Estado más autónomas y en particular, montajes de partido, que para mejor - y esta circunstancia es crucial - Iograron mantener en alto una competencia plural y relativamente paritaria, que marca el building originario y la civilización política que distingue al Uruguay.

En efecto, desde sus inicios y antes de que llegara la democracia, los partidos tradicionales mantuvieron una relación de fuerzas relativamente balanceada, alineados en el clivaje centro-periferia, en disputa en torno al poder incipiente del estado, cuya construcción va progresando dificultosamente en la segunda mitad del siglo XIX, por obra de las elites civiles y de los empujes del militarismo. Mal que bien, en ese período se celebraban elecciones, en base a un régimen mayoritario, falto de garantías y considerablemente excluyente, que generaba lealtades débiles y era desafiado - una y otra vez - por las guerras civiles. La secuela antagónica no dejó sin embargo saldos netos de ganadores y perdedores. La consigna con que había concluido la Guerra Grande en 1851 - "ni vencidos ni vencedores" - se convirtió en una pauta histórica emblemática, que desde aquella fecha moldea la vida política y el sistema institucional que se construye. En efecto, las confrontaciones en los campos de batalla resultaron en derrotas militares, pero no en el exterminio, la marginación o la sumisión terminante del bando derrotado, que seguía contando políticamente y de hecho mantenía capacidades de resistencia y potencial de amenaza. Siguiendo una regla universal en la materia, la democracia uruguaya prospera porque ninguno de los bandos adversarios pudo doblegar plenamente al otro, ni excluirlo: los blancos no pudieron con los colorados y los colorados no pudieron exterminar a los blancos, ni someterlos, ni tampoco prescindir de ellos.

${ }^{9}$ Ver las indicaciones de Renzo Pi sobre las características originarias de nuestra terra incognita y su población indígena, pobre en bienes, en sacerdotes y en caciques (PI, 1969). 
En este camino hacia la poliarquía pesa por tanto el balance de costos y beneficios - entre tolerancia y represión o entre tolerancia e insurrección - que lleva eventualmente al reconocimiento y la aceptación entre contrincantes e incluso a los acuerdos constructivos, con el fin de establecer reglas de convivencia y de competencia ${ }^{10}$. En virtud de ello y particularmente a partir de la Paz de Abril de 1872, los episodios de guerra civil desembocaron en una cadena de pactos de naturaleza constituyente, que fueron reformulando la institucionalidad pública - al margen de la Carta de 1830 - para albergar a los representantes de los dos partidos.

En realidad, el Estado sólo llegó a consolidarse como centro político monopólico, en la medida en que se configuró efectivamente como una estructura plural, con una pauta de corte "madisoniano", que dio espacio a las minorías y acotó la "tiranía de la mayoría", en lo que vendrá a ser una versión del "estado democrático de partidos" (KELSEN), muy temprana en el horizonte comparado, tanto en lo que respecta a América Latina, como en lo que respecta a Europa. Esto ocurrió paso a paso, gracias a sucesivos acuerdos políticos - aunque con discrepancias en el seno de los partidos y sobre todo dentro del coloradismo - mediante dos arreglos combinados, que procuraban el asentamiento de ambas colectividades en la institucionalidad que se iba edificando: a) la ampliación progresiva del número de bancas y de la representación proporcional en la sede parlamentaria; b) conjugada con la "coparticipación" en las estructuras administrativas del Estado, las cuales se fueron extendiendo, primero a nivel regional - mediante el reparto de las jefaturas políticas de los departamentos - y en seguida, a nivel nacional, con los nuevos organismos públicos.

Este proceso será coronado por la Ley de Elecciones Políticas de 1910, que precedió al establecimiento del sufragio universal masculino (Ley de 1912) y acuñó las bases del régimen electoral vigente hasta la reforma de 1996, convirtiéndose en una piedra angular del sistema político nacional.

El doble voto simultáneo fue el dispositivo estratégico de este régimen y permitió resolver de una vez dos grandes nudos de los sistemas político-partidarios: la competencia entre los partidos y al mismo tiempo la competencia entre fracciones, al interior de los partidos, en un esquema de pluralidad que se despliega en ambos círculos - inter partidario e intra partidario - en forma concurrente ${ }^{11}$. Combinada con las demás medidas de integración política adoptadas antes y después de 1910, esta ley fue un paso fundamental en la institucionalización del conflicto. De ahí en adelante, la competencia entre partidos y fracciones de partido pasará de las armas a las urnas y las elecciones irán convirtiéndose en el mecanismo regio de asignación de autoridad "the only game in town", según la gráfica expresión de Giuseppe Di Palma). Esto ocurría al mismo tiempo que se afirmaba el Estado y que se extendía la ciudadanía. Luego de una larga gestación y a cuenta de los procesos subsiguientes de consolidación, que culminan con la Constitución de 1917, puede decirse que la democracia uruguaya quedó inaugurada en esa fecha. Así pues, el año 2010 ha de tenerse como efemérides de un centenario muy relevante.

\footnotetext{
10 Tal cual proclama uno de los axiomas de Dahl (1971): "en la medida en que el precio de la supresión exceda el precio de la tolerancia, mayores son las posibilidades de que se dé un régimen competitivo".

${ }_{11}$ Por esas razones el doble voto simultáneo era defendido enfáticamente por José Espalter, Ministro del Interior del Presidente Williman (1907-11), cuyo gobierno promovió la iniciativa. Este método - ideado por el belga Jean Borely (1870) y reformulado por Justino Jiménez de Aréchaga (1884), un gran constitucionalista uruguayo - se ajustaba al designio pacificador de Williman, que insistía en el propósito de incluir a la oposición y ampliar la representación de las minorías, buscando un mecanismo que permitiera canalizar las divisiones coloradas y sobre todo, que sirviera para contener la abstención y el fraccionamiento de los blancos (VANGer, 1983; Diez De Medina, 1994). ¡No deja de ser revelador, en términos de civilización política, que el Presidente de la República se preocupara por la integridad de la oposición y buscara su inclusión institucional!
} 
LANZARO, J. Continuidad y cambios en una vieja democracia de partidos...

\section{Un trayecto originario de poliarquía}

La matriz pluralista se concreta en una trayectoria de poliarquía, dado que el building del sistema político fue modelado por el balance de fuerzas y dio nacimiento a una democracia presidencial, caracterizada por un grado considerable de distribución de los poderes públicos (BARRINGTON MOORE, 1966; DAHL, 1971; LANZARO, 2001). La “democratización fundamental” (MANNHEIM, 1940) se realiza en Uruguay a comienzos del siglo XX, mediante una serie de medidas relevantes: sufragio universal masculino, derechos civiles y primeros derechos sociales, garantías electorales, libertad de asociación, regulación del trabajo asalariado. Con esos componentes, la democratización propone una primera incorporación popular que es obra de los partidos y que sobreviene cuando las elites políticas ya habían pactado las reglas básicas de competencia y oposición. El ciclo cumple por tanto con los requisitos de una gestación poliárquica (DAHL, 1971).

En efecto, en el modelo uruguayo el pasaje de la política de elites a la política de masas - que es una coyuntura crítica fundamental - no se produce por ruptura, con la participación de actores desafiantes o de outsiders, sino que se tramita en clave de continuidad y por agentes competitivos que operan desde el seno del establishment. Los protagonistas principales de la democratización fundamental y de nuestro enfranchisement fueron las propias colectividades históricas, que - en su "policlasismo constitutivo" (PÉREZ, 1984) - han sido desde siempre partidos catch-all, con círculos de notables, pirámides de caudillos, bases en las capas medias y apoyos populares densos. En esta transición se convierten en partidos de ciudadanos, modernos, adoptando nuevas formas de organización, con cambios en la profesionalidad y en la estructura de liderazgo. La incorporación popular no fue protagonizada pues por un solo agente, sino que es de autoría conjunta de los dos partidos, de sus distintos sectores así como del juego cruzado de caudillos y doctores, en un trámite plural, cumplido en términos competitivos y balanceados.

Con acierto, los Collier ubican a Uruguay - junto a Colombia - entre los países de América Latina en los cuales la primera incorporación popular se cumplió por obra de partidos tradicionales, a diferencia de los casos de incorporación por obra del Estado o por movimientos populistas (COLLIER \& Collier, 1991). Sin embargo, adjudican dicho mérito al bat/lismo, como sector colorado de punta, cuando en rigor lo que hubo fue una incorporación de tipo competitivo y plural, con el activismo . conflictivo y a la vez concurrente - de los dos partidos históricos y de sus distintas fracciones.

Esta circunstancia contribuye a explicar que en esa coyuntura histórica no hayan surgido partidos o movimientos alternativos que organizaran políticamente a la clase obrera y a los sectores populares, convirtiéndose en abanderados del proceso de inclusión, en clave antagónica. También ayuda a explicar el hecho de que los partidos de filiación socialista que surgieron por entonces, tuvieran su origen en las clases medias ilustradas - sin bases obreras orgánicas - y cultivaran una impronta más bien reformista, exenta de arrestos revolucionarios efectivos, en una sintonía que se acomoda al sistema presidido por los partidos mayores y no promueve rupturas.

El pluralismo político permitió que prosperara el pluralismo social. En esa arena competitiva, las colectividades tradicionales afirman la vocación de catch-all parties que tuvieron desde siempre y más allá de ciertas proximidades, se cuidan de tener relaciones demasiado cercanas o exclusivas con clases sociales y grupos determinados, en el afán de mantener, en compases balanceados, una 
convocatoria abierta y diversificada. En correspondencia, los gremios empresariales, los sindicatos obreros que empezaban a formarse y las asociaciones de todo tipo, aunque tenían conexiones con sectores partidarios, tendieron a preservar cierta autonomía y debieron hacer efectiva su participación en una "group politics" renovada y pluralista. Las instituciones corporativas recién despuntaron hacia fines de los años 1920 y a partir de la década de 1930, floreciendo desde el recodo de 1942. Por lo demás, aunque en fases de crisis hubo empujes de corporativización de la política (notoriamente, en el correr de los años 1920 y de los 1960), en general, la centralidad del sistema de partidos - su institucionalización, su integración binaria, las lealtades que lo cimentan - Ileva a que las acciones corporativas se entablen mayormente con los partidos y a través de los partidos, sin que accesos de las clases al Estado que escapen abiertamente a las mediaciones partidarias (LANZARO, 1986; 1992).

La poliarquía originaria tuvo efectos constitutivos a largo plazo y sirvió para fundar una democracia pluralista duradera. En virtud de ello, el modelo uruguayo se distingue históricamente de otras configuraciones políticas de América Latina. Por un lado y en el extremo opuesto del espectro, nos diferenciamos del único caso de hegemonía realizada que ha existido en la región, el cual se erige como tal gracias a la Revolución Mexicana y a las construcciones institucionales consecutivas - en particular, las distintas armazones del partido oficial, las organizaciones de masas y las articulaciones corporativas - dando lugar a un régimen de monopolio muy estable y duradero. Por otro lado, nos diferenciamos de las situaciones más comunes, de hegemonías fallidas o de pluralismo trunco, con desequilibrio recurrente de poderes e inestabilidades congénitas, que se encuentran, por ejemplo, en biografías como la de Argentina o la de Bolivia, que a su vez son muy distintas entre sí $^{12}$.

\section{Una democracia consociational sui generis}

La matriz pluralista engendra una forma peculiar de democracia consociational (LANZARO, 1986; 2000a). Como se sabe, Arend Lijphart (1969) acuñó esta noción para identificar las construcciones democráticas y los procesos de unificación nacional en sociedades heterogéneas, fragmentadas en "sub. culturas" políticas antagónicas, a partir de clivajes de índole social (nacionalidad, etnia, religión, clase, familles spirituelles). Las democracias consociational surgen por lo general en pequeños países, en casos en los que existe cierto balance de poderes entre las distintas subculturas, mediante acuerdos de elites que buscan superar la fragmentación y alcanzar estabilidad sobre bases políticas asociativas. Estas fórmulas se traducen en una composición plural y no suponen un dominio unitario simple, sino que operan en base al reconocimiento de la diversidad, mediante arreglos apropiados de representación y participación, con "artefactos anti-mayoritarios" que tienden a consolidar un "cartel de elites" (DAHRENDORF, 1967). Aunque Lijphart manifiesta que tales arreglos dan lugar a dispositivos institucionales variados, en rigor identifica democracia consociational con gobierno consociational y más específicamente con diseños coparticipativos del Poder Ejecutivo. En este sentido, Austria y Bélgica son los casos más claros. También lo es Holanda, el país de origen de Lijphart y su leading case. En su lista

12 La historia de Argentina en particular - que es para los uruguayos una "otredad" fundamental, espejo y contra-ejemplo recurrente - ha sido vista como "un cementerio de hegemonías fallidas" (BotAnA, 1995). Pero también cabe detectar en el trayecto argentino varios momentos de pluralismo frustrado, en ciclos políticos que pueden considerarse como el reverso de nuestra peripecia, al dejar saldos drásticos de ganadores rotundos - aunque no hegemónicos - con perdedores que pierden por mucho (MORA y ARAUJo, 1982). 
LANZARO, J. Continuidad y cambios en una vieja democracia de partidos...

entran asimismo Suiza, el Líbano, Colombia y Uruguay, mientras tuvo Poder Ejecutivo colegiado, al "estilo suizo" (LIJPHART, 1969) ${ }^{13}$.

Considero que Uruguay ha sido históricamente un caso de democracia consociational, desde los procesos fundacionales y más allá de la vigencia del gobierno colegiado, con rasgos sui generis y en términos más amplios que los que sugiere Lijphart ${ }^{14}$. El análisis de nuestra experiencia, en el que aquí no corresponde extenderse (ver Castellanos \& Pérez, 1981), contribuye a enriquecer el cuerpo teórico de esta tipología de democracias. En efecto, en la variedad uruguaya la democracia consociational no se basa en clivajes sociales, sino que responde a un conflicto específicamente político - protagonizado por partidos de naturaleza catch-all - que se traba en torno al building del Estado y al clivaje centro-periferia. El Partido Colorado y el Partido Nacional eran de hecho "patrias subjetivas" (MARTínEZ LAMAS, 1930), que obraban como asociaciones para competir por el poder, a partir de una condición raigal de comunidades políticas - con sus tradiciones y sub-culturas, en base a identidades especulares, que construyen uno frente "al otro" (blancos contra colorados, colorados contra blancos) - labrando un antagonismo potente (PÉREZ, 1988). Como tales componen la nación, el Estado y el sistema político que contribuyen a edificar, mediante andamientos pluralistas que integran a ambas colectividades y a sus fracciones, proporcionando la clave constitutiva de la civilización uruguaya.

Esto no resultó en la debilidad de nuestro temple nacional, como a veces se cree y como el propio Martínez Lamas presumía en 1930. En rigor remite a una modalidad específica de construcción nacional: a un modo de ser, muy peculiar, cuya vitalidad radica precisamente en el acoplamiento de la pluralidad y en ese dualismo originario, que mantiene sus perfiles diferenciados y su vocación competitiva, pero ha de fundirse "dentro de una sola patria objetiva" (MARTínEZ LAMAS, 1930). Es más, ajustándose a una pauta que se encuentra asimismo en otros países pequeños y tal como suele ocurrir en las democracias consociational, esta circunstancia se convirtió en una condición de viabilidad y de hecho en un vector de fortaleza, con armazones consensuales internas que nos ubican mejor en el contexto externo, especialmente frente a los vecinos más cercanos. La contracara de ese principio constitucional - el precio del pluralismo - es por supuesto cierta morosidad en los procesos decisorios y la moderación en las políticas públicas.

Si bien el principio asociativo acota los resultados de la competencia en lo que toca a la distribución de poderes públicos - limitando el juego pleno de ganadores y perdedores - lo cierto es que, poco después de los primeros acuerdos partidarios de reparto regional, la fórmula se inserta en una estructura de competencia efectiva. Tanto las autoridades departamentales como las máximas jerarquías del gobierno nacional se disputan a través de carreras electorales abiertas, que van mejorando en efectividad y en garantías. Ambas dimensiones se retroalimentan y la competencia efectiva vendrá a

13 Uruguay tuvo casi treinta años de gobiernos colegiados, integrados por representantes de los dos partidos tradicionales (ver Nota 18). Ello ocurrió en dos períodos: el Consejo Nacional de Administración (1919-1933), que compartía competencias con el Presidente de la República, en una fórmula de ejecutivo "bicéfalo" y el Consejo Nacional de Gobierno (1952-1967), que era titular único del Poder Ejecutivo, sin que existiera un Presidente de la República.

14 De hecho, el propio Lijphart maneja la noción con amplitud y afirma que este tipo de democracia surge en realidad a través de diseños institucionales muy variados, que amplían los márgenes de representación y de participación de diferentes maneras. Encuentra así componentes de "consociationalism" en otros casos (LIJPHART, 1969, p. 225). Por ejemplo en los EEUU, gracias a los arreglos que siguen a la Guerra de Secesión y que mejoran ex profeso las posiciones de los representantes sureños a nivel nacional, particularmente en el Congreso. O bien en Dinamarca, en virtud de prácticas que no implican una política de compromisos en la sede ejecutiva, sino en la órbita parlamentaria. 
consolidar la condición generalista y plural - policlasista, catch-all - con la que ambos partidos accedieron a la política de masas.

La construcción uruguaya puede ser comparada con la que se establece en Colombia hacia mediados del siglo XX, dado que - a diferencia de los consocionalismos europeos - se aloja también en un régimen presidencial y fue gestada igualmente por los dos partidos históricos vernáculos (Conservadores y Liberales), operando como identidades tradicionales ("odios hereditarios"), con algún corte ideológico (anti clericales versus clericales), pero sin basarse estrictamente en clivajes sociales (DIX, 1980; HARTLYN, 1988). No obstante, nuestro diseño consociational es más antiguo que el colombiano y se distingue de éste en muchos aspectos. Por lo pronto, porque en Uruguay, para las instancias nacionales hubo desde siempre competencia efectiva, mientras que en Colombia se estableció al comienzo un régimen de paridad y alternancia pactada, acordándose que por dieciséis años (1958-1974), la presidencia fuera ocupada rotativamente por los dos partidos que conformaron el Frente Nacional ${ }^{15}$.

La coparticipación, el régimen electoral, la representación proporcional y el requerimiento de mayorías calificadas para las reformas constitucionales, así como para ciertas leyes y decisiones parlamentarias estratégicas, son factores decisivos en el proceso de institucionalización del pluralismo y en la construcción de nuestra singular democracia consociationa/16.

\section{Representación y coparticipación}

Las pautas de representación política y en particular el régimen electoral - con el diseño inicial que aporta la ley de 1910 - fueron pilares básicos del sistema pluralista que imperó durante el siglo XX. Como es sabido, en el ancien régime - que fue derogado por la reforma constitucional de 1996 - la elección presidencial a pluralidad, por mayoría simple de votos, se combinaba con una representación proporcional casi pura en el Parlamento y con el mecanismo del doble voto simultáneo para todos los cargos electivos que era una de las singularidades más sobresalientes del sistema uruguayo (GoNZÁLEZ, 1991; BuQueT, 2003; LANZARO, 2007b). Según esta regla, las elecciones nacionales y las disputas internas se ventilaban todas el mismo día y en un solo acto: las fracciones de un partido competían entre sí, pero al mismo tiempo acumulaban sus votos para competir contra los otros partidos, admitiéndose múltiples candidatos para todos los cargos nacionales y departamentales, inclusive para la Presidencia de la República. La fórmula fue una pieza estratégica del acto fundacional que vino a regular la competencia entre partidos, a la vez que incluía y regulaba la competencia al interior de cada partido.

Este ingenioso dispositivo reforzó la reproducción del bipartidismo y obraba como una medida de proteccionismo político, tanto de la unidad de cada conglomerado, como de su respectiva pluralidad interna, permitiendo que el conjunto del partido pudiera disponer de un buen rastrillo electoral. La apertura de la competencia interna daba herramientas para contrarrestar la "ley de hierro" de las oligarquías y favorecía la permanencia de los sectores de partido, manteniendo cierta fragmentación y un

${ }^{15}$ En el marco del Frente Nacional, la mayor parte de los cargos en el gobierno y en el estado (Gabinete, Senado, Cámara de Diputados, Suprema Corte, corporaciones públicas, órganos municipales) se repartían en paridad entre los dos partidos. Dentro del cupo correspondiente, la distribución de cargos se hacía en proporción a las bancas en el Congreso de las distintas fracciones de cada partido.

16 El sistema uruguayo cuenta con dos piezas constitutivas de todo régimen consociational: i) la representación proporcional, que es un pilar fundamental, máxime cuando no solo ancla en las cámaras parlamentarias y reconoce la diversidad en el seno de los partidos, sino que llega también a la administración ejecutiva; ii) conjugada con un principio de compromiso, que busca ensanchar el consenso y acotar el disenso al decidir sobre cuestiones políticas mayores. 
LANZARO, J. Continuidad y cambios en una vieja democracia de partidos...

grado variable de diferenciación ideológica17. En cada partido existían usualmente dos o tres fracciones, que obraban como actores relevantes en la escena política, con márgenes de autonomía considerables, delineando una suerte de bipartidismo fragmentario (AGUIAR, 1983).

El pluralismo y la proporcionalidad se alojan en las estructuras del Estado y modelan los procesos de gobierno, merced a la coparticipación en los órganos de la administración ejecutiva y al requerimiento de intervención parlamentaria, con mayorías especiales, para ciertas resoluciones estratégicas y también para nombramientos o promociones de alto rango (Suprema Corte de Justicia, Corte Electoral, Tribunal de Cuentas, Tribunal de lo Contencioso Administrativo, fiscales superiores, oficiales militares, embajadores).

La coparticipación comenzó a partir de la Paz de Abril de 1872, con la distribución de las jefaturas políticas departamentales, mediante acuerdos que reconocían los baluartes regionales de los dos partidos y de sus caudillos, asignándoles autoridad pública, posibilidades de patronazgo y de hecho una condición de "príncipes electores" para la integración de las Cámaras, que eran a su vez electoras del presidente. Estos pactos tuvieron una vida bastante azarosa, pero hicieron su camino en el building originario. Su ciclo se fue cerrando a principios del siglo XX, a medida que los departamentos pasaron a tener autoridades electas en régimen de libre competencia. Posteriormente, la coparticipación se instaló a nivel nacional. Por dos períodos (1919.33, 1952-67), el Poder Ejecutivo estuvo compuesto por un cuerpo colegiado, integrado en mayoría y minoría por representantes de los dos grandes partidos y de sus fracciones ${ }^{18}$.

De manera más permanente, la coparticipación moldeó la integración de las agencias de contralor y de los directorios de las empresas y servicios públicos, mediante una distribución de puestos que instala la proporcionalidad (apportionement) en organismos estratégicos de la administración ejecutiva descentralizada, más allá de los recintos parlamentarios. Con este régimen, los sectores de oposición - como tales - Iograban una participación directa en la gestión pública, con acceso a los recursos políticos y a las redes de clientela, por el solo hecho de disponer de representación parlamentaria y sin la exigencia de apoyos al gobierno, compromisos o coaliciones ${ }^{19}$.

17 Claro que hubo escisiones, sobre todo entre los blancos, perjudiciales para los partidos y especialmente para los que salían a la intemperie. En particular, la ruptura del Partido Nacional Independiente dividió a los blancos en dos y dañó adrede al sector "herrerista", desde comienzos de los 1930 hasta las reunificaciones de 1954 y 1958, desfigurando el bipartidismo tradicional por un buen trecho. Recién a partir de 1962, las nuevas coaliciones de izquierda y finalmente el Frente Amplio proporcionaron estructuras de recepción para los disidentes de filas tradicionales.

18 La idea del colegiado, al estilo suizo, fue propuesta por José Batlle y Ordóñez en sus famosos Apuntes de 1913, con una integración "monocolor", en la que todos los cargos de consejero quedaban en manos del partido ganador. Paradójicamente, la fórmula se adoptó en la Constitución de 1917, pero con una estructura bipartidaria y sirvió para frenar el "avancismo" de Batlle y Ordóñez. Con un esquema similar, fue usada en 1951 para limitar las potencialidades de Luis Batlle Berres, el abanderado del segundo batllismo. En ambas ocasiones mediaron reformas constitucionales realizadas por sectores conservadores blancos y colorados, en contra de dichos liderazgos progresistas, dando lugar al colegiado bipartidista que Lijphart toma en cuenta para incluir a Uruguay en la lista de las democracias consociational.

19 Aunque los mapas de ruta son muy distintos, este régimen puede compararse con el "proporz" austríaco: una regla de distribución de los altos puestos de la administración pública, en proporción a la representación parlamentaria, que los partidos pusieron en obra en la segunda post-guerra, como engranaje de uno de los ejemplares más notables de democracia consociationa (ProporzDemokratie). En este caso, la coparticipación operaba en el marco de la "Gran Coalición" entre la Democracia Cristiana y el Partido Socialista, al influjo de parcialidades partidarias que recubrían a su vez otros cortes sociales, envolviendo en particular las relaciones entre los sindicatos de trabajadores y los gremios empresariales. La regla alcanzaba a las jerarquías de la burocracia, las empresas nacionalizadas y los servicios sociales (como educación o vivienda), aportando recursos de patronazgo que beneficiaban a los dos grandes partidos en consorcio. En Costa Rica - como pieza de la bipolaridad que luego dio paso al bipartidismo - también ha habido experiencias de coparticipación en los directorios de los organismos públicos descentralizados, que no tienen sin embargo una proyección equiparable. Prácticas similares se encuentran asimismo en Colombia. 
Descentralización y coparticipación fueron condiciones claves para la habilitación del Estado "ampliado", cuyo desarrollo se ajustó a los principios políticos originarios y vino a consolidar la democracia pluralista (LANZARO, 2004a). En efecto, la incorporación de nuevos cometidos económicos y sociales, no redundó simplemente en un refuerzo de las facultades del Poder Ejecutivo o del Presidente, en régimen de concentración de la autoridad pública. Por el contrario, a partir de la reforma constitucional de 1917 y con los acuerdos posteriores (en especial el "Pacto del Chinchulín" de 1931), la ampliación de las competencias públicas quedó sujeta a una pauta de descentralización y de coparticipación que modeló el desarrollo de la estructura política del estado a lo largo del siglo XX. Siguiendo tal principio político-institucional, si bien fue creciendo el número de ministerios y se multiplicaron sus dependencias - en un modelo jerárquico - buena parte de los cometidos que se fueron agregando quedaron a cargo de la administración descentralizada, bajo la dirección de cuerpos colegiados y autónomos, en régimen de coparticipación.

En una suerte de "pluralidad de gobiernos", se gestó así un archipiélago de centros políticos sectoriales, con recursos de poder considerables - celosos de su autonomía con respecto a los ministerios - que controlaban los procesos decisorios en áreas estratégicas de la actividad pública (bancos, energía, transportes, puertos, comunicaciones, educación, seguridad social, etc.) ${ }^{20}$.

Junto a estas formas de coparticipación partidaria, desde fines de la década de 1920 habrá instancias de coparticipación corporativa, no sólo a través de los "anillos" formales e informales, que enlazan a los agentes de clase con las burocracias estatales, sino además y en pasos importantes de institucionalización, en base a organismos tripartitos y bipartitos, integrados por representantes del gobierno, los empresarios y los trabajadores. A partir de los años 1940, este circuito corporativo especializado - en una posición secundaria frente al Parlamento y al gobierno, a la ciudadanía política y al sistema de partidos - dio lugar a formas paralelas de representación, abrigó la segunda incorporación obrera y reforzó la ciudadanía social, aportando nuevos formatos para la inclusión de los sindicatos y de los cuadros de izquierda que los dirigían.

Estos organismos corporativos, que se fueron multiplicando al prosperar el Estado de bienestar y la versión uruguaya del keynesianismo periférico, componían el círculo de las personas públicas no estatales y tuvieron a su cargo la administración de algunas ramas importantes de la seguridad social, así como varias de las funciones de regulación de la economía y del trabajo (LANZARO, 1986; 1992) ${ }^{21}$.

Sin perjuicio de este segmento corporativo, Uruguay es un ejemplo sobresaliente de estado de partidos. A su vez, los partidos tradicionales fueron - en conjunto y desde un principio - partidos de estado, cuya reproducción (organización, carreras políticas, recursos de poder, pautas de legitimación, sistema de linkages con los ciudadanos y los agrupamientos sociales) quedó asociada al Estado que esos

20 Las reformas constitucionales de 1966 y de 1996 atenuaron la autonomía de los organismos descentralizados, tratando de reivindicar la primacía del gobierno central en la conducción política de los servicios. En la década de 1960, esto ocurrió al influjo del desarrollismo, con posturas inclinadas al planeamiento y al dirigismo centralizado. Posteriormente, al cundir los propósitos de reforma del estado, dicha tensión se plantea en forma cada vez más tirante, con pulseadas de poder y de hecho con algunos pasos, más o menos visibles, en favor de la rectoría del centro gubernamental. Esto ha ocurrido en forma palpable al correr los años 1990, con los gobiernos de inspiración liberal; pero también desde el 2005 y crecientemente, en la primera administración de la izquierda y durante la segunda.

${ }^{21}$ Este tipo de instituciones corporativas no son privativas de los regímenes autoritarios, fascistas o populistas. Al contrario, son mucho más comunes como piezas constitutivas de los regímenes democráticos, tanto en Europa como en América Latina, en forma generalizada a partir de los años 1920 y durante la era keynesiana (SHONFIELD, 1965; SCHMITTER, 1974; LANZARO, 1998). 
LANZARO, J. Continuidad y cambios en una vieja democracia de partidos...

mismos partidos concurrieron a edificar, reformándolo en repetidas coyunturas históricas, como parte estratégica de los cambios en el modelo de desarrollo y en la estructura política.

\section{La Gran Transformación}

En la década de 1960 el modelo político reseñado y el sistema de partidos en que se sustentaba tuvieron una crisis mayúscula, que condujo a la dictadura. En el curso de la siguiente transición democrática y en la etapa que se abre a continuación, el sistema de partidos recuperó consistencia y centralidad, pero experimentó una transformación de gran calado, marcada por el desarrollo de la izquierda nucleada en el Frente Amplio y el fin del bipartidismo tradicional. Esta transformación adquiere más vuelo con la transición liberal que se despliega a partir de 1990 y culmina quince años después, con el estreno de la izquierda en el gobierno nacional.

\section{La transición liberal}

Las transiciones democráticas y las transiciones liberales de las últimas décadas en América Latina varían país a país, debido a distintos factores y en particular según el peso que han tenido en cada caso los partidos y los sistemas de partidos. El grado de "partidicidad" (partyness) de estos procesos, es una variable fundamental que se refleja en el rumbo de las transiciones y en los tipos de democracia que surgen de ellas, así como en la forma de las reformas liberales y en sus resultancias (CORRALES, 2000; FRANCO \& LANZARO, 2006).

Uruguay atravesó por los tres procesos que han signado la historia de América Latina desde los años 1980 - las transiciones democráticas, la transición liberal y el giro a la izquierda - y en esos tres procesos los partidos han sido agentes decisivos, siendo a la vez seres mutantes, dado que ellos mismos y el sistema que conforman experimentan una "transición en la transición" (LANZARO, 2007c).

En efecto, en la transición democrática - que se resuelve en un proceso de reordenamiento del sistema político y de recomposición de sus principales actores - los partidos tuvieron un desempeño cada vez más activo, sacaron a luz sus identidades (sofocadas, pero vivas, durante la dictadura) y paso a paso, fueron recuperando centralidad. Una vez restaurada la democracia, son los partidos los que hacen punta en la "segunda" transición y la competencia que se traba entre ellos modela la fase de reformas de corte liberal (LANZARO, 2000a). En este ciclo el Partido Colorado y el Partido Nacional avanzaron las iniciativas reformistas, sin que mediara - como en otros países - una situación crítica detonante. Más allá de las influencias del "clima de época", el proceso fue más bien el fruto de una competencia activa entre los dos partidos y dentro de los partidos, entre sus diversos sectores, con una tríada de liderazgos rivales potentes $^{22}$. Las propuestas más alineadas con las ideologías al uso en aquel momento vinieron de las alas de centro-derecha de ambas colectividades. Movidos por esa competencia inter e intra partidaria, blancos y colorados, junto con algunos intelectuales orgánicos, actuaron en esa fase como promotores de la agenda neoliberal, abogando por la reforma del Estado y de la economía, a través de las campañas electorales y mediante una ofensiva ideológica que tuvo visos de "revolución cultural" y contribuyó a que se fuera asentando el giro de época. Desde el gobierno, impulsaron las privatizaciones y

22 A partir de 1989 - que es un año clave y en varios aspectos un parteaguas - el ciclo quedó marcado por la competencia entre tres liderazgos, todos ellos enérgicos pero de distinto tipo, de sesgos ideológicos diferenciados y de diverso potencial de gobierno: la contraposición de Jorge Batlle y Julio Ma. Sanguinetti en el Partido Colorado, cruzada con la que despliega Luis Alberto Lacalle desde el Partido Nacional (LANZARO, 2000a; 2000b). 
desmonopolizaciones, los cambios en el Estado, la liberalización de los mercados y los flujos de mercantilización, delineando nuevas pautas de gestión pública y de regulación económica y social.

La competencia en filas tradicionales - con posiciones distintas y enfrentamientos a veces acerados - acusó además los efectos de la tercería de la izquierda, que ejerció una oposición cerrada. Por añadidura, hubo varias instancias de participación ciudadana, con plebiscitos constitucionales y recursos de referéndum destinados a bloquear las privatizaciones en el sector público. Sin embargo, a diferencia de lo que ha ocurrido en otros países latinoamericanos, los actos de democracia plebiscitaria no surgen como emprendimientos populistas, ni derivan de la debilidad del sistema de partidos. Por el contrario, si bien obraron como instancias de alzada con respecto al circuito representativo y a las resoluciones parlamentarias, obedecieron a las tácticas de los partidos, en particular a las movilizaciones de veto emprendidas o amparadas por el Frente Amplio, en yunta con la fraternidad sindical.

Debido a estos cruces de competencia política las reformas fueron gradualistas y moderadas, con un perfil que limitó la liberalización y preservó las funciones del Estado en mayor medida que en otros países de América Latina (LANZARO, 2000a; FORTEZA et al 2007)23. A más de los frenos surgidos ex post, hubo ajustes ex ante de las iniciativas políticas e incluso, varias de las reformas aplicadas resultaron heterodoxas con respecto a los cánones neoliberales ${ }^{24}$. Si bien los flujos de mercantilización resultaron importantes y los servicios públicos fueron permeados en cierta medida por las lógicas privatistas y empresariales, hubo partes considerables del viejo Estado de bienestar que quedaron en pie y uno tras otro, los gobiernos de distinto pelo pusieron en práctica nuevos paquetes de políticas sociales. No obstante - con estas características - la coyuntura crítica de la transición liberal tuvo consecuencias políticas palpables y en el trayecto, se produjo una suerte de "transición en la transición", con efectos especialmente importantes en lo que toca al gobierno, el sistema de partidos y las estructuras de competencia (LANZARO, 2000a; 2007c).

\section{Innovación Política y Reforma Constitucional}

A medida que el FA creció como partido desafiante, crecieron también los acuerdos y las alianzas entre el Partido Colorado y el Partido Nacional, delineándose una política de bloques. Los partidos tradicionales se turnaron en la presidencia y fueron estrechando poco a poco su cooperación, mediante aprendizajes y nuevos experimentos, con pases de compromiso y estrenando coaliciones de gobierno que tuvieron su versión más potente en el segundo mandato de Sanguinetti, cuando predominó un liderazgo presidencial orientado hacia el centro. Uruguay se sumó así a la ola de "presidencialismo de coalición", que tiene en Brasil su patria privilegiada (ABRANCHES, 1988), pero desde los años 1990 se extiende por varios países de América Latina, en pleno auge del reformismo liberal y en escenarios multipartidistas (LANZARO, 2001). Las coaliciones permitieron formar mayorías parlamentarias, sostener las políticas liberales y promover reformas, que en nuestro caso fueron de todos modos incrementales y

23 En el Índice de Privatizaciones de Lora (LORA, 2001), durante el periodo 1985-1999 - que es el ciclo de alza de las tendencias neoliberales. Uruguay figura en último lugar entre los 18 países de América Latina, con el valor más bajo de activos públicos privatizados en proporción al PNB (menos del 0,1\%). Brasil está en el tercer puesto (más de $10 \%$ del PNB), seguido de Argentina (justo debajo de 9\%), en un ranking encabezado por Bolivia (casi 20\%) y Perú (15\%). Según el Índice de Privatizaciones actualizado, en 2009 Uruguay seguía figurando último entre los 18 países de América Latina (LoRA, 2012).

24 Particularmente la reforma educativa comandada por Germán Rama (LANZARO, 2004b), pero también la reforma de la seguridad social, mal vista en su momento por el Banco Mundial (ForTeZA, 2007; MeSA-Lago \& Bertranau, 1998). 
LANZARO, J. Continuidad y cambios en una vieja democracia de partidos...

moderadas, merced a la competencia entre los partidos asociados y al contrapunto con la oposición de izquierda.

En el nuevo escenario político se alteraron las prácticas de coparticipación. En efecto, durante la primera presidencia de Sanguinetti (1985-90), a la salida de la dictadura, el FA se incorporó a la coparticipación y tuvo sitios en directorios de varios entes estatales. Fue de hecho un reconocimiento de la tercería de la izquierda y del papel que ésta había tenido en la transición democrática, obrando como una de las medidas tendientes a reforzar el proceso consecutivo de consolidación y de integración política. Cuando el FA creció como fuerza de oposición y se gestaron coaliciones entre los dos decanos del sistema de partidos, esta disposición cambió y durante tres períodos consecutivos (1990-2005), el FA fue excluido de la coparticipación. Esta pasó a tener un carácter coalicional, beneficiando solamente a quienes mantuvieran conductas de proximidad respecto al gobierno. El instituto perdió por tanto sus trazas históricas, que incluían a la oposición como tal y que habían sido recompuestas en la post. dictadura, acogiendo el nuevo esquema tripartidista, en una extensión del pluralismo que después se dejó de lado.

En 1996, a fin de demorar la llegada del Frente Amplio al gobierno y hacerla depender de un apoyo político mayor, los partidos tradicionales impulsaron una reforma constitucional que desmanteló el régimen electoral construido a principios del siglo XX. En términos tipológicos, esta fue una reforma de carácter defensivo, impulsada por una coalición "declinante" (BUQUET, 2007), que operó como una alianza de "dos contra uno", típica de los escenarios en tríada (CAPLOW, 1974). No obstante - en virtud de los balances generados por la competencia inter e intra partidaria y merced a la voluntad política de los líderes principales de la coalición reformista - esta estrategia buscó regular el conflicto político y contemplar al adversario, extendiendo el consenso y tratando de limitar el disenso. Tales pautas modelaron tanto la procesalidad como el contenido de la reforma, que fue elaborada por una comisión integrada por todos los partidos, contó con el apoyo de dirigentes del FA de primera línea y no solo atendió a los intereses de los diferentes sectores blancos y colorados integrantes de la coalición, sino que incorporó buena parte de las demandas históricas de la izquierda. Ello contribuyó a reducir el agravio de los destinatarios contra los cuales iba dirigida la operación reformista, reforzando su legitimidad.

La reforma constitucional uruguaya de 1996 quedó pues plenamente encuadrada en la democracia de partidos - en los marcos de un sistema plural y competitivo, de robustos contrapuntos de oposición efectiva - adoptando un perfil por cierto muy distinto al que presentan las reformas constitucionales de corte adversativo y sin núcleos de oposición debidamente organizados, tramitadas en democracias sin partidos y con ínfulas anti-partido, que han proliferado en las última décadas en algunos países de América Latina (notoriamente en Bolivia, Ecuador y Venezuela).

El nuevo diseño rompe con los principios vertebrales del ancien régime, ya que elimina el doble voto simultáneo y adopta reglas mayoritarias para la elección presidencial, en dos vueltas con ballottage y en base a candidaturas únicas, surgidas de elecciones primarias, obligatorias y simultáneas para todos Ios partidos (BUQUET, 1998; LANZARO, 2007b). Se mantuvo sin embargo la representación proporcional para la elección parlamentaria, que se cumple en forma concurrente y definitiva con la primera vuelta presidencial. 
OPINIÃO PÚBLICA, Campinas, vol. 19, no 2, novembro, 2013, p. 235-269

La competencia política dio pie a innovaciones en el gobierno presidencial y condujo a una reforma constitucional que impuso cambios sustanciales en el régimen electoral. Estos cambios fueron tramitados en los marcos de la democracia plural de partidos y generaron a su vez consecuencias políticas importantes, tanto para el FA como para los partidos tradicionales, los cuales - como suele ocurrir - terminaron siendo prisioneros de sus propias innovaciones institucionales.

\section{Realineamiento del Sistema de Partidos}

El nuevo régimen no frenó las tendencias que motivaron la reforma. El realineamiento electoral siguió su curso y la transformación histórica se consolidó, acarreando cambios en la estructura general del sistema de partidos, así como en el lugar y la función sistémica de cada partido. El dominio del bipartidismo tradicional tocó a su fin y el FA continuó creciendo: en 1999 se convirtió en el partido más grande del arco político uruguayo y al ganar las elecciones de 2004 hizo su debut en el gobierno.

Tabla 2

Elecciones Nacionales 1971-2009

Votos por Partido (\%)

\begin{tabular}{|l|c|c|c|c|c|c|c|}
\hline & 1971 & 1984 & 1989 & 1994 & 1999 & 2004 & 2009 \\
\hline Partido Colorado & 41 & 41 & 30 & 32 & 33 & 11 & 18 \\
\hline Partido Nacional & 40 & 35 & 39 & 31 & 22 & 35 & 30 \\
\hline Frente Amplio & 18 & 21 & 21 & 31 & 40 & 50.5 & 48 \\
\hline Nuevo Espacio & $\cdot$ & $\cdot$ & 9 & 5 & 5 & & \\
\hline Partido Independiente & $\cdot$ & $\cdot$ & $\cdot$ & $\cdot$ &. & 2 & 3 \\
\hline
\end{tabular}

Fuente: Banco de Datos FCS - Área Política y Relaciones Internacionales: http://www.edu.uy/pri.

Este proceso se despliega en varias elecciones críticas, en el curso de un cuarto de siglo. El debut de la izquierda en el gobierno se produce a 33 años de la fundación del FA y 20 años después de las elecciones de apertura de 1984 que franquearon la vuelta a la democracia. Es por ende un proceso gradual, que tiene lugar en un marco de estabilidad democrática y de competencia efectiva. El sistema de partidos mantiene su integridad y pone a prueba su institucionalización, a pesar y a través de los cambios, transitando hacia una nueva estructura plural, siempre competitiva, en la cual los alineamientos políticos y la disputa electoral, se traban en torno al clivaje izquierda-derecha. El desarrollo del FA contribuye a que este clivaje se afirme en forma más explícita que durante el predominio de la competencia entre blancos y colorados, sirviendo como eje de identificación y reconocimiento a nivel de las élites partidarias y de los votantes ${ }^{25}$. Por lo demás, al afirmarse como fuerza desafiante en términos de integración competitiva y no de ruptura, con los ojos puestos en una eventual alternancia, el FA obra también como "válvula de seguridad" política, poniendo lo suyo para mantener la capacidad de agregación del sistema de partidos en una coyuntura crítica.

25 Uruguay es uno de los países de América Latina en el que el clivaje izquierda-derecha muestra una consistencia significativa y es reconocido como tal en las encuestas de opinión y los estudios de cultura política, en términos de identidades políticas y de auto-identificación ideológica, tanto a nivel de élites como de ciudadanía. Según los datos del Latinobarómetro para el período 1995-2010, el porcentaje de personas que en Uruguay no se identifican en ese eje es relativamente bajo, se ubica en general alrededor del $10 \%$ y resulta menor que el promedio (entre $20 \%$ y $30 \%$ ) registrado para el conjunto de la región (www.latinobarometro.org). Sobre la dimensión izquierda-derecha en América Latina, ver el análisis comparativo de Colomer \& Escatel (2005). 
LANZARO, J. Continuidad y cambios en una vieja democracia de partidos...

La competencia política es el motor y la clave de explicación del realineamiento electoral (LANZARO, 2000a; 2007c). Al procesarse la transición democrática y en el curso de la transición liberal, los partidos tradicionales tuvieron una performance razonable, básicamente en tres aspectos relevantes de la política y del party government en ese ciclo histórico: postulación de la agenda reformista, innovación en los modos de gobierno presidencial y renovación de sus liderazgos, sus cuadros y sus programas. Paradójicamente, tales éxitos salieron caros, ya que fueron perdiendo apoyo electoral de manera sistemática.

Los procesos de liberalización, la reforma del Estado y en particular las privatizaciones, se convierten en eje estratégico de la competencia partidaria e inciden de manera decisiva en el realineamiento político. Una parte del electorado acompaña la "revolución reformista", mientras que otra se ubica en actitudes de resistencia y de rechazo, con posturas acordes a la tradición estatista que ha predominado históricamente en el Uruguay ${ }^{26}$. Esa inclinación del electorado uruguayo es alta y en esa fase se ubica entre las más altas de América Latina ${ }^{27}$. Pero el clivaje estado-mercado resulta afirmado por la competencia política que se despliega desde los años 1990, siendo alimentado por las acciones del FA y de los sindicatos, en su antagonismo con los blancos y los colorados. A tal punto que, una vez que el FA llega al gobierno, ese antagonismo pierde fuerza y el estatismo de la opinión pública uruguaya, aunque sigue siendo alto, rebaja en algo sus marcas ${ }^{28}$.

Las reformas de signo liberal y las mutaciones en la economía afectaron la naturaleza de partidos de estado que tuvieron desde el origen las colectividades tradicionales y redujeron sus recursos de poder, particularmente en lo que respecta a los objetos, las formas, el alcance y los márgenes de discrecionalidad en la asignación política de bienes públicos. Sus propias acciones reformistas y los cambios concurrentes alteraron la condición de partidos "keynesianos" que ostentaron en las distintas etapas del Uruguay batllista, mediante el cultivo sistemático de la producción y distribución de bienes, servicios públicos y prestaciones reguladoras (LANZARO, 1994). Estas circunstancias modifican las pautas de legitimación y el sistema de linkages (KITSCHELT, 2000) con los ciudadanos, los agentes económicos y las organizaciones colectivas, en particular las redes de clientela.

A ello se suman los efectos de las nuevas formas de competencia y cooperación que los partidos tradicionales ponen en práctica, con pautas que se ven reforzadas por el régimen electoral establecido por la reforma constitucional de 1996. Desde 1990, a medida que el FA crece, blancos y colorados acuden a una progresiva convergencia y forman coaliciones, presentando un grado creciente de indiferenciación. No hay un nuevo bipartidismo, pero de hecho, ante la emergencia de un tercero desafiante, los viejos rivales históricos pasan a constituir un polo político, delineando incluso un "círculo

26 Los datos de la serie estadística del Latinobarómetro 1995-2002 confirman que en Uruguay el clivaje estado-mercado y en particular, la opinión pública acerca de las privatizaciones, constituyen en estos años los mejores indicadores de intención de voto (LANZARO \& LUNA, 2002). El electorado en general muestra un alto nivel de estatismo, pero los votantes del FA son más estatistas que los votantes de los demás partidos. En correspondencia, mientras que el FA está consistentemente asociado a la defensa del estado, los partidos tradicionales aparecen asumiendo posiciones más pro-mercado.

27 Así lo indican sistemáticamente las series del Latinobarómetro (www.latinobarometro.org) y así lo muestra también, en forma muy significativa, el resultado del referéndum de 1992 que derogó . por una mayoría rotunda (70\% de votos) - la ley que autorizaba la privatización de empresas públicas.

${ }^{28}$ En efecto, en las series del Latinobarómetro, mientras que a principios de la década del 2000 Uruguay se ubica en 3.6 en la escala estado-mercado (1-10), hacia el fin de la década esa marca va ascendiendo y en el año electoral de 2009 se ubica en 4.4 (www.latinobarometro.org) 
de familia"29. Como resultado de la superposición ideológica y de la asociación política, se les hace cada vez más difícil cultivar sus tradiciones, preservar su identidad y articular opciones aptas para la competencia triangular, entre ellos y de cara al Frente Amplio.

También disminuye la diferenciación interna y con ello las posibilidades de rastrillo electoral que proporcionaba anteriormente la coexistencia de sectores de derecha y de izquierda en los partidos tradicionales. En ambos conjuntos persiste la diversidad ideológica. Pero la competencia del FA y los requerimientos de la acción política con apoyos parlamentarios reducidos, inducen a la convergencia interna y exigen mayor disciplina partidaria. El régimen electoral sancionado en 1996 permite que la pluralidad de partidos se manifieste en la primera vuelta, pero aumenta las complicaciones y tiende a pronunciar las tendencias indicadas, ya que impone una secuencia de "eliminatorias", con efectos de concentración y dificultades de competencia, al interior de los partidos y entre partidos "vecinos".

Por lo tanto, cabe sostener que la pérdida electoral de los partidos tradicionales es en parte consecuencia de sus propias estrategias: la ofensiva liberal que encabezaron y los recursos defensivos que pusieron en obra ante el crecimiento de la izquierda. En rigor, en la coyuntura crítica que les tocó afrontar a partir de la transición democrática, los partidos tradicionales - por acción o por reacción, movidos por la competencia inter e intra partidaria - terminaron por erosionar los pilares sobre los cuales se cimentaba su dominio a lo largo del siglo XX.

\section{EL FA de partido desafiante a ¿partido predominante?}

Ciertamente, tales movimientos operaron en un escenario signado por la emergencia del FA como partido desafiante. La transformación de la izquierda y sus estrategias de competencia en el marco específico de la democracia de partidos son factores claves para explicar la forma que adopta el realineamiento electoral. De otra manera, la transición liberal hubiera podido conducir a evoluciones políticas diferentes y eventualmente a una desarticulación del sistema de partidos, tal como ha ocurrido en otros países de América Latina: dependiendo precisamente de la fortaleza del sistema de partidos, su grado de competitividad en condiciones críticas y en ciclos de mutación, su capacidad de control y su capacidad de adaptación en los procesos de cambio (MAIR, 1997). La transición liberal ha sido una fase de "darwinismo político" para los partidos (COPPEDGE, 2001), que plantea serios desafíos y al mismo tiempo abre posibilidades. El sistema de partidos uruguayo cambió mucho, pero ha salido bien parado del trance. Ello es debido a la supervivencia de los partidos tradicionales, pero también, a que el FA aprovechó la estructura de oportunidad, transitó por un proceso de adaptación partidaria, cambió bastante y se desarrolló como un partido exitoso, lo que en definitiva resultó benéfico para la propia izquierda y para el sistema en su conjunto.

La prosperidad del FA se explica por factores que remiten a dos procesos concatenados, que acunan el realineamiento electoral y tienen implicaciones históricas de gran calado (LANZARO, 2004): i) la "nacionalización" de la izquierda, que viene de los años 1960 y se afirma en los lances posteriores; ii) su plena integración a la democracia de partidos y muy en particular, el ajuste de sus estrategias políticas a

29 Según cálculos elaborados en base a las encuestas de Cifra y de Equipos-Mori, la superposición entre el Partido Colorado y el Partido Nacional que en 1984 cubría alrededor del 77\% del electorado, quince años después, en 1999, Ilega al 90\%. En el mismo período, la distancia ideológica entre ambos partidos baja del $12 \%$ al 3\%, dibujando por tanto una "círculo de familia". 
LANZARO, J. Continuidad y cambios en una vieja democracia de partidos...

los requerimientos de la disputa electoral y la conquista del gobierno, en un sistema de partidos consistente, plural y altamente competitivo.

En uno de los sentidos corrientes que la noción tiene en la Ciencia Política ${ }^{30}$, la "nacionalización" se refiere a la cobertura regional de un partido y a su proyección para el conjunto de un país, lo que supone redes de organización extendidas y un proceso de diversificación política que concuerde con el mapa de particularidades locales, articulando propuestas, candidaturas y vínculos adecuados. El FA fue en sus inicios y por un buen tiempo, una fuerza urbana, preponderantemente asentada en Montevideo, que desde 1971 a 1989 recogió en esta plaza entre 70\% y 75\% de sus apoyos. A partir de 1994 tiende a "nacionalizarse" en términos regionales y va creciendo en otros departamentos. En las elecciones nacionales, sus votantes en el Interior pasan del $10 \%$ entre 1971 y 1989 , a $19 \%$ en 1994 y a 31\% en 1999, para ubicarse en 44\% en 2004 y en 2009, año en el cual, por primera vez, el porcentaje de votos que el FA recabó en el Interior $(52,8 \%)$ supera al porcentaje de sus votos en Montevideo (47,2\%). En las elecciones municipales de 2005, el FA - que ha gobernado en Montevideo en forma ininterrumpida desde 1990 - conservó este bastión (con el $61 \%$ de votos de un departamento que concentra el $42 \%$ del electorado) y conquistó 7 intendencias más, pasando a administrar 8 de los 19 departamentos (73\% de la población y más de tres cuartos del PBI). En las municipales 2010, el FA mantuvo Montevideo, aunque con un porcentaje inferior (58\%). En el Interior retuvo tres intendencias y ganó una, pero perdió 4, quedando en total con cinco.

La "nacionalización" de la izquierda ha de ser analizada asimismo en términos políticos, ideológicos y culturales, en una noción semejante a la utilizada por Antonio Gramsci en sus Quaderni del Carcere (1929-1935). Como he planteado en mi periodización de la izquierda uruguaya (LANZARO, 2004), ello supone la composición de ofertas políticas de proyección nacional que superen, tanto el "cosmopolitismo" y los postulados universalistas (las invocaciones "internacionalistas" y el socialismo "abstracto"), como los postulados particularistas (sectoriales o de clase), para realizar proposiciones más concretas y de vocación general, con respecto a la realidad específica del país.

Esta "nacionalización" implica también la conexión de la identidad partidaria propia con tradiciones nacionales emblemáticas, mediante una competencia ideológica pertinente, que permita hacer valer una relectura de la historia y proponga de hecho una "reinvención" de la tradición (como diría Eric Hobsbawm), entrando a tallar efectivamente en la "disputa por la nación" y en las producciones de sentido común. En el caso de la izquierda uruguaya, los pasos fundacionales de este emprendimiento tienen lugar en la década de 1960, acompañando la saga política que desemboca en la fundación del FA, merced a una multiplicación de intervenciones intelectuales, de vocación ideológica "contra-hegemónica" frente al establishment tradicional - potenciadas por la prédica educativa, las publicaciones de divulgación masiva, el canto popular y otros hechos de cultura - que signan el despegue de la nueva izquierda ${ }^{31}$.

La nacionalización, que obra hacia adentro y ha de calar en la feligresía partidaria, debe asimismo ganar audiencia pública. A ello contribuye la participación en procesos políticos significativos

30 Ver en particular Jones \& Mainwaring (2003), que proponen un índice para medir la nacionalización partidaria (Party Nationalization Score).

${ }^{31}$ La reinvención y cierta apropiación de la figura de Artigas - nuestro héroe nacional -, junto con la adopción de emblemas patrios, es una pieza importante y exitosa del empalme entre pasado y presente que la izquierda cultiva en los 1960. 
que acreditan el implante nacional, el compromiso democrático y de hecho la legitimación de la izquierda. En este anclaje juegan las biografías dinásticas, los martirios de la dictadura, así como el desempeño de la izquierda en la transición democrática y su integración política consecutiva. El general Seregni, que fue en estos trances un conductor certero y un referente mayor - en el ruedo partidario, en los círculos de las elites y entre el público común - hace con ello su propio aporte, dando pruebas de que en los procesos de nacionalización los liderazgos cuentan. El protagonismo nacional del FA se irá asentando en las instancias posteriores, primero como cabeza de una oposición organizada y luego como actor de gobierno.

En la fase constitutiva de los años 1960 se produce un enlace decisivo que moldea los procesos genéticos de los que surge el FA y tiene consecuencias duraderas. Las composiciones partidarias que van labrando los nuevos formatos de la izquierda institucional (1962-1971), se articulan con el acrecimiento de la militancia de los sindicatos y la constitución de la Convención Nacional de Trabajadores (CNT: 1964-1966) como central única, lo que proporciona las dos pistas mayores del desarrollo del bloque de oposición emergente: una partidaria y otra sindical.

En el momento en que la izquierda se apresta más decididamente para la competencia electoral y pasa para ello por un primer capítulo de los procesos de adaptación partidaria, se registra asimismo la expansión y una reconfiguración política del dominio que venía cultivando en los sindicatos, desde los umbrales de la década de 1940 (LANZARO, 1986). Ese dominio, que se extiende también en el movimiento estudiantil y en los mundos de la cultura, viene acompañado de un esfuerzo de colonización del sistema educativo, que a la larga resultará exitoso, con alcances variados en sus distintos niveles y con una proyección que se sobrepone a la dictadura y logra posteriormente desarrollos manifiestos.

El lanzamiento de la izquierda como fuerza desafiante tiene su expresión mayor en la competencia electoral, pero implica una movilización más amplia y comprende la disputa por el control de aparatos ideológicos, que resultan estratégicos en los procesos de reproducción social y para las gestaciones de sentido común. Los asentamientos que se conquistan en tales aparatos son un vector de apoyo en la fase de crecimiento del FA, pero no dejan de albergar un contencioso de poderes, entre tendencias contrapuestas y particularmente, entre fracciones de la propia izquierda. El arribo a la presidencia plantea un nuevo escenario, con un patrón de vínculos entre el gobierno, el partido de gobierno y sus anclajes sociales, que experimenta sucesivas modificaciones. El estreno abre asimismo nuevas arenas para el contencioso entre sectores frenteamplistas, que se instala en las "tres caras" del gobierno - administración ejecutiva, parlamento, partido - así como dentro de los distintos aparatos del Estado y entre ellos, dando lugar a una competencia redoblada, referida al reparto de cargos, los recursos de poder y las orientaciones políticas.

Con esos antecedentes, la estrategia política del FA en el ciclo ascendente (1989-2005) se resuelve en su desarrollo como partido catch-all, de profesión electoral (KIRCHHEIMER, 1966; PANEBIANCO, 1982), lo cual implica cambios en su ideología y en su organización, en los procesos decisorios y en la estructura de liderazgo. Estos procesos de adaptación partidaria pasan por una competencia externa e interna, intensa e incesante, acompañada de una disputa por el liderazgo que en el caso del FA se ajusta a la pauta exitosa de un "transformismo" balanceado: con cambios importantes pero al mismo tiempo moderados, que cultivan la identidad de partido y preservan muchas de las adquisiciones de su 
LANZARO, J. Continuidad y cambios en una vieja democracia de partidos...

trayectoria, manteniendo cierta densidad organizativa y recursos de poder que se van acumulando. En esta senda el FA renueva los vínculos con las clases medias y el movimiento obrero, consolida su enraizamiento en redes estratégicas del Estado, extiende sus alcances urbanos y rurales, logrando incluso una llegada novedosa e importante en los sectores populares, en áreas en las que antes reinaban Ios blancos y colorados (LANZARO, 2004; LUNA, 2007). Su perfil de "partido de integración" - con votantes "devotos", referentes de clase y una fuerte hermandad con el movimiento sindical - da paso a una política de ciudadanos y a una nueva textura de partido "popular", con márgenes amplios para la representación individual y para los votantes "sueltos". La intensificación de la competencia electoral, en jornadas que se multiplican a raíz de la reforma de 1996, se suma a la participación en plebiscitos y actos de referéndum - que menudean entre 1989 y 2004 - y engrana con las instancias internas de elección de autoridades, va reconfigurando la organización y las formas de activismo, mediante prácticas que rebajan la militancia tradicional, insisten en convocar a los fieles de la izquierda en calidad de votantes y ensanchan las franjas en que el FA se comporta como un "partido de electores".

En ese periplo el FA pone en obra una estrategia "two-pronged": que levanta una oposición cerrada frente a los partidos tradicionales - renegando de la liberalización y en particular de las privatizaciones - pero se combina al mismo tiempo con la moderación ideológica y el empeño firme de conquistar nuevos votantes, sin perder a los suyos, alineándose en la competencia hacia el centro. Para este empeño ayuda mucho la estructura de "partido de coalición" (LANZARO, 2000) - unificado, pero con alta fragmentación - que el FA va construyendo a partir de su modelo genético, la cual proporciona un espectro ideológico diversificado y un buen rastrillo electoral. Ayuda también el control de la Intendencia de Montevideo, ininterrumpido desde 1990.

La estrategia del FA resultó exitosa. Fue aumentando su caudal electoral en forma sistemática durante veinte años y ganó la elección nacional de 2004 en primera vuelta, por mayoría absoluta, asegurándose el control de ambas Cámaras, algo que no ocurría en Uruguay desde $1966^{32}$. Al estrenarse en el gobierno nacional el FA ostenta una clara primacía política y cabe preguntarse si no estamos ante una configuración de partido predominante, retomando interrogantes que se planteaban en referencia al Partido Colorado, en épocas del bipartidismo tradicional.

Es verdad que el FA no cumple el requisito de obtener mayoría absoluta de bancas parlamentarias en tres elecciones consecutivas, que acreditaría el status predominante según los cánones propuestos por Duverger (1960) y Sartori (1980)33. Habrá que ver si esa circunstancia se concreta en las elecciones de 2014, teniendo en cuenta que la marca electoral de 2004 no se repite en 2009 y por el contrario, se interrumpe la racha ascendente de las dos décadas previas (1984-2004): en

32 En términos de representación parlamentaria esta situación no se daba desde el triunfo del Partido Colorado en 1966 o de Partido Nacional en 1958. Para registrar antecedentes de mayoría absoluta de votos en las elecciones y no sólo de bancas parlamentarias, hay que remontarse más atrás aun, a la performance del Partido Colorado en 1950 y 1954.

${ }^{33}$ Duverger (1960) propuso una noción de partido dominante, más simple que la que había acuñado en su obra de 1951: las elecciones no son meramente plebiscitarias, sino competitivas, "pero hay un partido más grande que los otros, que tiene por si solo la mayoría absoluta de las bancas parlamentarias", por un período prolongado (ejemplos: los radicales franceses en la Tercera República, los partidos social demócratas en Escandinavia, el Partido del Congreso en India). Veinte años después, Sartori (1980) retomó esa noción y propuso un criterio operativo convencional: habrá un sistema de partido predominante, siempre que un partido conquiste la mayoría absoluta de bancas parlamentarias ("no necesariamente de votos"), en tres elecciones consecutivas. Tanto Duverger como Sartori afirman que la "dominancia" puede existir como patrón histórico, aunque no se haga efectiva en una elección determinada. 
2009 el FA pierde votos, consiguiendo por segunda vez mayoría absoluta en las Cámaras, gracias a las reglas electorales y con un margen más ajustado ${ }^{34}$.

No obstante, puede considerarse que el conglomerado de la izquierda ha conseguido una posición de cierto predominio, observando otros aspectos. En primer lugar, porque desde 1999 el FA es el partido más grande a nivel nacional ${ }^{35}$, en un horizonte en el que los partidos tradicionales han encontrado dificultades para componer una oferta política conducente y retomar la iniciativa que tuvieron antes, a partir de la transición democrática y cuando corrían a favor del paradigma prevaleciente, al impulsar la transición liberal. Por lo demás, el FA administra Montevideo en forma ininterrumpida y con comodidad desde 1990, habiendo conquistado, aquí sí, la condición de partido predominante (aunque su record de 61\% de votos montevideanos del 2005 bajó a 58\% en 2010). En 2005 el FA ganó siete intendencias más y en el 2010 quedó con cinco, registrando un descenso también a este nivel, pero con dos triunfos seguidos en departamentos importantes del país.

Por otra parte, el FA ha llegado a ser un gran partido popular, catch-all, manteniendo una convocatoria electoral que llega a un espectro extenso de capas sociales, desde las clases medias a los sectores populares, en la capital y en el interior (LANZARO \& DE ARMAS, 2012). Maneja una oferta política relativamente abarcadora y el arco ideológico de sus votantes - de la izquierda hacia el centro - también es amplio. A eso hay que agregar la hermandad de la izquierda con los sindicatos y el perfil laborista que tuvo el primer gobierno del FA, así como el control de aparatos ideológicos estratégicos - con visos hegemónicos en la educación y en los círculos de la cultura - mediante relaciones cultivadas durante décadas y con raíces hondas. Por más que la práctica del gobierno reformule estos vínculos y los distienda, generando complicaciones y conflictos, con aristas diferentes, tanto en las dos administraciones frenteamplistas, como en cada área de actividad.

En el proceso de transformación del sistema de partidos, los partidos tradicionales - que han sido secularmente partidos de estado - fueron acercándose al perfil de carte/-parties (KATZ \& MAIR, 1995): con formas de reproducción y modalidades de competencia inter e intra partidarias, carreras políticas, recursos de poder, fuentes de financiamiento y red de vínculos con la ciudadanía, que pasan a depender del Estado en mayor grado de lo que pudo ocurrir anteriormente. Con su asentamiento en la Intendencia de Montevideo y más marcadamente desde su estreno en el gobierno nacional, el FA va incorporándose a la condición de partido de estado y a su modo, también entra en los usos de la "cartelización". Sin

${ }^{34}$ En la propuesta inicial de Duverger (1951), el partido predominante, además de su condición mayoritaria prolongada, era el que se "identificaba con la nación", encarnando de alguna manera las ideas de la época (ejemplos: el Partido Radical en la Tercera República Francesa o los partidos social demócratas en Escandinavia). En esa tipología podía incluirse al Partido Colorado de Uruguay, que para más de un autor era un partido predominante (FITZGIBBON, 1957; ALMOND \& COLEMAN, 1960; SARTORI, 1980): porque estuvo 90 años en el gobierno (1868-1958), pero también por el peso que tuvieron las corrientes batllistas de ese partido en dos períodos fundamentales de la historia uruguaya y particularmente, en base a la visión de que en el primer tercio del siglo XX, José Batlle y Ordóñez fue el "creador de su tiempo" (VANGER, 1963). Como vimos más arriba, esa tipificación no se compagina con la dinámica pluralista que tuvo el sistema uruguayo en tiempos del bipartidismo: aun cuando no hubiera alternancia, merced a los registros de competencia efectiva, a las pautas de intercambio partidario y a las prácticas concretas de gobierno. Considero que tampoco en este sentido corresponde calificar al FA como un partido predominante. No sólo porque sería prematuro concluir que la alternancia de la izquierda inauguró una "era progresista" - aunque en la presidencia de Vázquez haya habido una siembra de innovaciones importantes - sino por las mismas razones que llevan a negar ese rango al Partido Colorado y en concreto, atendiendo a las circunstancias que se exponen a continuación, en este mismo apartado y en el

siguiente.
35 Esto corresponde a la "idea general" de partido predominante expuesta por Sartori (1980): "un partido que supera de lejos a los otros" y tiene "alrededor de 10 puntos porcentuales de diferencia" respecto a los otros partidos, un umbral que el FA sobrepasa tanto en 2004 como en 2009. 
LANZARO, J. Continuidad y cambios en una vieja democracia de partidos...

embargo, lo hace con una ventaja comparativa, ya que si bien su organización partidaria fue cambiando, ha perdido densidad y ha perdido poder, sigue siendo relativamente robusta y logra influir en algunas decisiones relevantes, a pesar de que el centro de gravedad de la política se traslade a los circuitos de gobierno. Además, aun con cambios importantes y un cierto debilitamiento de sus redes, el FA preserva sus arraigos sociales. De hecho, el conglomerado de la izquierda se desenvuelve como un partido "anfibio": que se interna cada vez más en las aguas estatales, pero en cierta medida, también mantiene sus pies en los terrenos de la sociedad.

No hay duda que la izquierda ha conquistado mucho peso en la distribución de poderes. Sin embargo, a diferencia de lo que ocurre en otros países de la región (LANZARO, 2008), el sistema uruguayo sigue siendo plural y competitivo, con un régimen de oposición efectiva. De modo que esas tendencias podrían eventualmente revertirse, sobre todo a nivel electoral, existiendo incluso la posibilidad de una alternancia, en la medida que el FA rebaje su convocatoria, si los partidos de oposición recuperan iniciativa y logran articular candidaturas y ofertas políticas conducentes.

\section{El estreno de un gobierno social-democrático}

El debut de la izquierda uruguaya en el gobierno nacional (2005-2010) inauguró una alternativa de tipo social-democrático en Uruguay (LANZARO, 2011a), que vino a sumarse a las que surgieron en Brasil y Chile desde el umbral del 2000, con las presidencias de Lula da Silva, Ricardo Lagos y Michelle Bachelet. La aparición de este tipo de gobierno depende de la existencia de una democracia de partidos y resulta precisamente de las estrategias de competencia política en el cauce de un sistema de partidos institucionalizado, plural y competitivo, como es el uruguayo.

El surgimiento de una generación de gobiernos de este tipo constituye una novedad absoluta para América Latina, en donde - al igual que en otras comarcas - el término se emplea con demasiada amplitud y hay otras figuras que se denominan social-democráticas ${ }^{36}$. Algo similar ha ocurrido en Uruguay, sobre todo en referencia al primer batllismo y al segundo, pero también a expresiones más recientes. No obstante, es la primera vez que existen en nuestra región experiencias que corresponden stricto sensu al concepto de gobiernos social-democráticos - no necesariamente de regímenes social. democráticos - en base a una definición teórica que atiende a la naturaleza política específica de tales gobiernos.

En efecto, según la tipificación que he presentado en otros trabajos (LANZARO, 2008; 2011b), los gobiernos social-democráticos son aquellos formados por partidos de izquierda institucionalizados, crecidos en estrecho vínculo con el movimiento sindical y de filiación socialista (aunque no necesariamente de tal nombre), que han atravesado por procesos de cambio político y llegan a reemplazar sus ideologías revolucionarias o radicales por un reformismo moderado pero efectivo, como resultado de las estrategias electorales y las orientaciones políticas que adoptan. Por definición y como factor crucial, los procesos de adaptación partidaria, las carreras electorales y el desempeño de

${ }^{36}$ Por ejemplo: los gobiernos de Liberación Nacional en Costa Rica, de Acción Democrática en Venezuela o de Fernando Henrique Cardoso y su Partido da Social Democracia Brasileira. A su vez, la posibilidad de una alternativa social-democrática para nuestra región ha sido postulada por algunos intelectuales (Helio Jaguaribe y el propio Fernando Henrique Cardoso; José María Maravall, Luiz Carlos Bresser-Pereira \& Adam Przeworski, Jorge Castañeda y Roberto Mangabeira) y también por actores políticos, incluyendo a dos protagonistas conspicuos de estas experiencias, Lula da Silva y Ricardo Lagos, que antes de ser presidentes participaron en las propuestas del Ilamado "Consenso de Buenos Aires" (1997). 
gobierno, se cumplen en democracias representativas, con competencia efectiva, en el marco de sistemas de partidos plurales, más o menos institucionalizados.

Este concepto es consistente con las proposiciones clásicas sobre el "socialismo electoral"37 y se aplica a las nuevas figuras latinoamericanas. Define también a los ejemplares europeos "clásicos", de la primera generación - los únicos que según algunos merecen la "appellation" de origen - que se desarrollaron a partir de la crisis de 1930 y en la post-guerra siguiente, en una articulación muy propicia con la era keynesiana, que estaba en pleno auge y que pudo favorecer la construcción de un "régimen" de compromiso social-democrático (BERGOUNIOUX \& MANIN, 1979). Habrá posteriormente otra generación, más "rezagada", que surge en Europa del Sur en las décadas de 1970 y 1980 (GALLAGHER \& WILLIAMS 1989; MARAVALL, 1992; MERKEL, 1995).

Las experiencias de España, Portugal y Grecia, que asoman con distinto potencial en esta segunda tanda, se dan en países subdesarrollados de la periferia de Europa Occidental, con economías dependientes y sociedades atrasadas, muy desiguales, sometidos a regímenes autoritarios (en Portugal y España durante buena parte del siglo XX), registrando debilidades en los pilares social-democráticos típicos: los partidos de filiación socialista y los sindicatos ${ }^{38}$. Esto ayuda a explicar los desafíos que los gobiernos social-democráticos debieron afrontar y el perfil de sus agendas, en términos de democratización política, de aggiornamento cultural y en calidad de "modernizadores tardíos" de la economía y de la sociedad ${ }^{39}$.

Cabe pues identificar generaciones de gobiernos social-democráticos que por su naturaleza política corresponden todas ellas al concepto enunciado, pero se establecen en etapas históricas distintas y en distintas regiones - en el contexto de diversos modelos de desarrollo del capitalismo - con rasgos constitutivos comunes y a la vez con diferencias significativas: en lo que refiere al contexto general y a las condiciones concretas de emergencia, la clase de problemas que afrontan y las restricciones en que deben moverse, la configuración política, los recursos de poder y las resultancias de cada gobierno. Encontramos así desafíos y agendas diferentes, con diversas capacidades de innovación y productos variados en lo que respecta a la democracia y el desarrollo, la regulación económica, las políticas sociales y el montaje de regímenes de bienestar ${ }^{40}$.

\footnotetext{
37 Ver en particular: Kirchheimer (1966), Bergounioux \& Manin (1979; 1989), Przeworski \& Sprague (1986), Kitschelt (1994), Przeworski (2001). El "parliamentary socialism" cultivado desde siempre por el Labour Party en Inglaterra, excluye por principio y desde el principio toda opción revolucionaria e implica incluso una moderación sistemática del reformismo de izquierda (MILIBAND, 1972)

38 El hecho de que en ciertos países de América Latina puedan registrarse características similares lleva a algunos autores a dudar de la posibilidad de que surjan experiencias social-democráticas en la región (por ejemplo: Roberts (2008), Weyland et al 2010).

39 Un impulso importante para tales propósitos provino de la integración europea y sus instituciones, un circuito al que los países en cuestión pugnaron por entrar y que actuó como amparo internacional y a la vez como incentivo para las coaliciones internas y las acciones reformistas.

40 La existencia de fórmulas social-democráticas con posteridad a las ediciones clásicas, no es pacíficamente admitida. Dio pie a interrogantes y polémicas al instalarse los gobiernos socialistas en Europa del Sur en el último tercio del siglo XX, que se replantean al caracterizar las variedades de gobiernos de izquierda que surgen en América Latina a principios del siglo XXI. Por lo demás y particularmente en Europa, hay en curso un debate sobre los desafíos presentes y sobre el destino de la social democracia a partir del brote neo-liberal y al desatarse la crisis actual. La discusión se redobla y adquiere visos dramáticos en aquellos casos en que los partidos de corte social-democrático han sido desplazados del gobierno, especialmente en Chile y en España.
} 
LANZARO, J. Continuidad y cambios en una vieja democracia de partidos...

\section{Hacia una nueva norma política}

Al recorrer la senda social-democrática y en función de las estructuras de competencia que condicionan sus estrategias políticas y su empeño electoral, los partidos de la izquierda institucional se integran a las reglas de la democracia representativa. Esto es así no sólo en lo que refiere a las elecciones, como "the only game in town", camino que recorren asimismo las otras izquierdas que triunfan en la etapa actual de América Latina, sino también en lo que respecta a la institucionalidad de gobierno y al conjunto de restricciones políticas vigentes en un sistema plural competitivo. El acatamiento de las restricciones políticas los lleva a incorporar las restricciones económicas. A raíz de ello se avienen a la lógica de la economía capitalista, en mercados abiertos, lo que implica a la vez cierta continuidad con el status quo y con los parámetros predominantes en la fase de liberalización.

Cabe pensar que se dibuja así un policy regime (PRZEWORSKI, 2001), que contribuye al asentamiento de un "paradigma" normativo (ROBERTSON, 1976): gobiernos de distinta filiación ideológica aplican políticas similares por obra de las condicionantes que imperan y en función de cálculos electorales. Efectivamente, esto es lo que de hecho sucede - en distinta medida y en las diferentes arenas de políticas públicas - con variaciones importantes, país a país y caso a caso. No obstante, estos gobiernos tratan a la vez de impulsar orientaciones distintivas en áreas estratégicas. Esto ocurre fundamentalmente a causa de su matriz ideológica y del contencioso interno del bloque gobernante, factores ambos que se cruzan y que cuentan mucho. Responde asimismo a las propias determinaciones de la competencia inter partidaria, que por un lado lleva a la moderación, pero al mismo tiempo induce a poner en obra la "lógica de la diferencia”, en una dura lex de la dinámica política ${ }^{41}$

La combinatoria entre continuidad e innovación, en ancas de un reformismo incremental y ya no de la revolución de las sociedades capitalistas, promovido por izquierdas institucionales, dentro de regímenes políticos estables, plurales y competitivos, es lo que define a los gobiernos social. democráticos, en sus diversas generaciones. Esto vale igualmente para los ejemplares de la social democracia criolla, que han surgido en América Latina.

Por cierto, el potencial social-democrático depende de los recursos políticos de cada gobierno, que según he propuesto (LANZARO, 2008) remite a las siguientes dimensiones: a) los legados institucionales y los patrones de políticas públicas heredados; b) el coeficiente de poder del gobierno y del partido de gobierno, en relación al sistema de partidos y en su caso a la coalición de gobierno, medido por los respaldos parlamentarios y otros factores concurrentes; c) el poder del partido de izquierda en relación al gobierno que forma y al propio presidente, con diverso grado de influencia política; d) las características y la organización del movimiento sindical, así como el tipo de relación que este tiene con el gobierno y el partido de gobierno; e) relación del gobierno y del partido de gobierno con la población ubicada en las franjas de pobreza, con los desocupados y con los trabajadores informales, no organizados u organizados por fuera de los circuitos sindicales corrientes.

\footnotetext{
${ }^{41}$ En una línea teórica clásica, hay múltiples trabajos que hacen hincapié en las diferencias de orientación política derivadas de la ideología y de la acción de los partidos, incluyendo análisis específicos sobre las experiencias social-democráticas. Ver por ejemplo las investigaciones de más porte, que son referencia obligada en la materia (CASTLES, 1982; BoIX, 1996; o GARRETT, 1998), así como la argumentación de Maravall (1992) o el abordaje de Merkel \& Petring (2008), centrados en los gobiernos de la izquierda europea de las últimas décadas.
} 
Durante la presidencia de Vázquez, el FA tuvo un alto coeficiente de poder y fue titular de un gobierno mayoritario, de un solo partido. Había un liderazgo presidencial consistente, el jefe de gobierno era a la vez jefe unitario del partido de gobierno y el Consejo de Ministros integró a los dirigentes de los sectores del FA, dando lugar a una suerte de gobierno de gabinete en régimen presidencial. A ello hay que agregar un relevo importante en las elites políticas, merced al estreno de los cuadros de izquierda en el gobierno nacional, que tiene efectos sensibles, pero no "sísmicos", ya que resulta de un proceso gradualista, contando con varios años de propedéutica política.

Por su condición mayoritaria, el gobierno no se vio obligado a formar coaliciones ni a celebrar compromisos parlamentarios y optó por prescindir de la oposición, en forma tajante. Además, blancos y colorados quedaron fuera de la coparticipación en las empresas del Estado y los servicios públicos, tal como le había ocurrido al FA entre 1990 y 2005. Recién con el segundo gobierno del FA, llegará la restauración del viejo mecanismo de la coparticipación, que por iniciativa del presidente Mujica vuelve aplicarse en base a su principio originario y ajustándose a la nueva estructura del sistema de partidos.

La performance del gobierno estuvo acorde con la magnitud de sus recursos de poder y en ancas de una notable bonanza económica, aprobó un conjunto de disposiciones que delinean una agenda social-democrática relevante ${ }^{42}$. Las innovaciones fueron significativas y ello coloca a Uruguay como ejemplo de punta entre las experiencias social-democráticas latinoamericanas (LANZARO, 2011a), tanto por las políticas adoptadas, como por la institucionalización que las encuadra ${ }^{43}$. También hubo continuidades en áreas estratégicas de política nacional e internacional, así como en las líneas generales del modelo de desarrollo capitalista. Por cierto, no faltaron las debilidades y en algunos de los rubros que más exigían - como la educación - se notó la cortedad o la ausencia flagrante de las iniciativas.

Por tanto, la alternancia - pacífica - no fue en modo alguno trivial y aunque es discutible que tenga un alcance fundacional tan marcado como el que los representantes oficialistas suelen proclamar, la llegada al gobierno del tercer partido, que además es el más grande, aparece sin duda como un mojón decisivo en el ciclo de rotación histórica de las últimas décadas ${ }^{44}$. Los cambios resultan importantes en términos de políticas públicas y - lo que no es menor - se ajustan a las reglas democráticas y pasan por procesos de construcción institucional. Sin embargo, esta alternancia tampoco fue "brusca" o radical. Aun contando con recursos de poder de gran magnitud, el estreno de la izquierda no incurrió en ejercicios de mayoría "arriesgada" y se apegó a una pauta de reformismo moderado - del centro hacia la izquierda - típica de los gobiernos social-democráticos. Lo hizo dentro de la lógica incremental y de los carriles de institucionalización que tienden a prevalecer en los regímenes plurales y competitivos, acotando el riesgo de futuros vuelcos revisionistas. De hecho, puede decirse que predominó una vez más el gradualismo y ese código genético de sociedad "amortiguadora" (REAL DE AZúA, 1984), que la democracia de partidos brinda al Uruguay.

42 Ver al respecto los Informes de Coyuntura del Instituto de Ciencia Política 2006-2009 y del Instituto de Economía 2005-2009. Ver también Huber \& Pribble (2011) y Lanzaro (2011a).

43 Particularmente en derechos humanos y manejo de las herencias de la dictadura, regulación económica y disciplina fiscal, reforma tributaria y reforma de la salud, ciencia y tecnología, inversiones en capital humano, relaciones laborales y políticas sociales.

44 Queda abierta la pregunta, planteada asimismo para otros gobiernos de izquierda en América Latina, sobre la posibilidad de delinear un paradigma alternativo, con otros modelos de desarrollo capitalista o un nuevo desarrollismo. 
LANZARO, J. Continuidad y cambios en una vieja democracia de partidos...

Al cabo del cuarto de siglo transcurrido desde la transición democrática, la mutación histórica delinea una nueva norma política que supone la persistencia de nuestra singular democracia de partidos, con una reconfiguración mayor del sistema de partidos y modificaciones importantes en la política y el Estado, en el régimen electoral y en las pragmáticas de gobierno, que tuvieron como protagonistas a los partidos tradicionales y a la izquierda emergente. El estreno del FA en la presidencia nacional - que en sí mismo implica un giro relevante - puede verse como un paso de "normalización", que corona un proceso de muchos años. En el centenario de la ley de Elecciones de 1910, piedra angular de nuestra formación democrática, un juego sinuoso de cambios y continuidades produce el relevo en las estructuras de competencia e implica la instalación de otra normalidad, que reemplaza a la que predominó durante la égida del bipartidismo tradicional.

\section{Referencias Bibliográficas}

ABRANCHES, S. "Presidencialismo de coalizão: o dilema institucional brasileiro". Dados, vol.31, n 1, 1988.

AgUIAR, C. Elecciones Uruguayas. Montevideo: CIEDUR, 1983.

AldRICH, J. Why Parties? The Origin and Transformation of the Political Parties in America. Chicago: University of Chicago Press, 1995.

Almond, G. \& Coleman, J. (eds.). The Politics of Developing Areas. Princeton: University Press, 1960.

AltMAN, D.; LIÑÁN, A. P. "Assessing the Quality of Democracy: Freedom, Competitiveness and Participation in Eighteen Latin American Countries". Democratization, 9, 2002.

Araujo, M. M. “El ciclo político argentino”. Desarrollo Económico, n 86, 1982.

AzúA, C. R. Uruguay ¿una sociedad amortiguadora? Montevideo: Ediciones de la Banda Oriental, 1984.

BARRÁN, J. P. \& NAHUM, B. El problema nacional y el estado: un marco histórico. En: La crisis uruguaya y el problema nacional. Montevideo: Ediciones de la Banda Oriental, 1984.

BentLey, A. The Process of Government. Chicago: University of Chicago Press, 1908.

Bergounioux, A. \& Manin, B. La social-démocratie ou le compromis. Paris: PUF, 1979.

Le régime social-démocrate. Paris: PUF, 1989.

BobBio, N. El futuro de la democracia. México: FCE, 1991.

BORELY, J. Représentation proportionelle de la majorité et des minorités. Paris: Germer Baillière, 1870

BotanA, N. "Las transformaciones institucionales en los años del menemismo". En: SidicARo, R. y MAYER, J. (eds.). Política y Sociedad en los Años del Menemismo. Buenos Aires: UBA, 1995.

Boıx, C. Partidos políticos, crecimiento e igualdad. Estrategias económicas conservadoras y socialdemócratas en la economía mundial. Madrid: Alianza Editorial, 1996.

BuQuet, D.; CASTEllano, E. "Representación proporcional y democracia en Uruguay". Revista Uruguaya de Ciencia Política, 8, 1995

BUQUET, D. "Reforma política y gobernabilidad democrática en el Uruguay: la reforma constitucional de 1996". Revista Uruguaya de Ciencia Política, 16, 1998.

"El doble voto simultáneo". Revista SAAP, 1-2, 2003 
. "Entre la legitimidad y la eficacia: reformas en los sistemas de elección presidencial en América Latina". Revista Uruguaya de Ciencia Política, 10, 2010.

Caetano, G.; Rilla, J.; Pérez, R. "La partidocracia uruguaya. Historia y teoría de la centralidad de los partidos". Cuadernos del CLAEH, 44, 1988

CAPLow, T. Dos contra uno: teoría de coaliciones en las tríadas. Madrid: Alianza Universidad, 1974.

Carroll, R. \& Shugart, M. Neo-Madisonian Theory and Latin American Institutions. In: Munck, G. (ed.). Regimes and Democracy in Latin America. New York: Oxford University Press, 2007.

Castellanos, A.; Pérez, R. El pluralismo. Examen de la experiencia uruguaya 1830-1918. Montevideo: CLAEH, 1981.

CASTLES, F. (ed.). The Impact of Parties. London: SAGE, 1982.

Collier, D.; Collier, R. B. Shaping the Political Arena. Princeton: Princeton University Press, 1991.

Colomer, J. \& Escatel, L. "La dimensión izquierda y derecha en América Latina". Desarro/lo Económico, 45, 2005.

Coppedge, M. Strong Parties and Lame Ducks. Presidencial Partyarchy and Factionalism in Venezuela. Stanford: Stanford University Press, 1994.

. Political Darwinism in Latin America's Lost Decade. In: DIAmOND, L.; GUnTHER, R. (eds.). Political Parties and Democracy. Baltimore: The Johns Hopkins University Press, 2001.

Corrales, J. "Presidents, Ruling Parties and Party Rules. A Theory on the Theory of Economic Reform in Latin America". Comparative Politics, 32, 2000

DaAlder, H. "Parties: Denied, Dismissed or Redundant?" In: Gunther, R.; Montero, J. R.; Linz, J. (eds.). Political Parties. Old Concepts and New Challenges. New York: Oxford University Press, 2002.

DAHL, R. Polyarchy: Participation and Opposition. New Haven: Yale University Press, 1971.

DAHRENDORF, R. Society and Democracy in Germany. New York: Double Day, 1967.

DI PALmA, G. To Craft Democracies. University of California Press, 1990.

Dıx, R. "Consociational Democracy: The Case of Colombia". Comparative Politics, 12, 1980.

Drake, P. Between Tyrany and Anarchy. A History of Democracy in Latin America, 1800-2006. Stanford: Stanford University Press, 2009.

Duverger, M. Les Partis Politiques. Paris: Armand Colin, 1951.

"Sociologie des Parties Politiques". In: Gurvitch, G. (ed.). Traité de Sociologie. vol. 2 . Paris: PUF, 1960.

ERrandonea, A. M. "El mutacionismo electoral como indicador de estabilidad política". Revista Uruguaya de Ciencias Sociales, $n^{\circ} 2,1972$.

FitzGibBon, R. "Party Potpurri in Latin America". Western Political Quarterly, 1/X, 1957.

FortezA, A. et al. Pro-Market Reform in Uruguay: Gradual Reform and Political Pluralism. In: FAnELLI, J. M. (ed.). Understanding Market Reforms in Latin America. New York: Palgrave MacMillan, 2007.

Franco, R. \& Lanzaro, J. (eds.). Política y Políticas Públicas en los Procesos de Reforma en América Latina. Buenos Aires: Miño \& Dávila, 2006

Gallagher, T.; Williams, A. (eds.). Southern European Socialism Manchester. Manchester University Press, 1989.

Garrett, G. Partisan Politics in the Global Economy. New York: Cambridge University Press, 1998.

GonzÁLEZ, L. "Legislación electoral y sistema de partidos: el caso uruguayo". Revista Uruguaya de Ciencia Política, 4, 1991

Estructuras políticas y democracia en Uruguay. Montevideo: FCU, 1993.

HARTLYN, J. The Politics of Coalition Rule in Colombia. Cambridge: Cambridge University Press, 1988. 


\section{LANZARO, J. Continuidad y cambios en una vieja democracia de partidos...}

.; Valenzuela, A. "Democracy in Latin America since 1930". In: Bethell, L. (ed.). Latin America Politics and Society since 1930. The Cambridge History of Latin America. Cambridge: Cambridge University Press, 1998.

HOFSTADTER, R. The Idea of a Party System. Berkeley: University of California Press, 1969.

HUbER, E. \& PribBle, J. Social Policy and Redistribution under Left Governments in Chile and Uruguay. In: LEVITSKY, S.; RoberTs, K. (eds.). The Resurgence of the Latin American Left. Baltimore: The John Hopkins University Press, 2011.

Huntington, S. Political Order in Changing Societies. New Haven: Yale University Press, 1968.

Jiménez de Aréchaga, J. La libertad política. Montevideo: Librería Nacional, 1884.

Jones, M.; Mainwaring, S. "The Nationalization of Parties and Party Systems". Party Politics, 9-2, 2003.

Katz, R.; MaIR, P. "Changing Models of Party Organization and Party Democracy. The Emergence of the Cartel-Party". Party Politics, 1-1, 1995.

KITSCHELT, H. The Transformation of European Social Democracy. New York: Cambridge University Press, 1994.

. "Linkages between Citizens and Politicians in Democratic Politics". Comparative Politics, 33 - 6/7, 2000.

Lamas, J. M. Riqueza y Pobreza del Uruguay. Montevideo: Palacio del Libro, 1930.

LANZARO, J. Sindicatos y sistema político: Relaciones corporativas en el Uruguay, 1940-1985. Montevideo: Fundación de Cultura Universitaria, 1986.

"Los partidos uruguayos: del keynesianismo criollo a un nuevo gobierno político". En: VALDÉs, L. (ed.). El fin de siglo y los partidos políticos en América Latina. México DF: Instituto Mora, 1994.

El fin del siglo del corporativismo. Caracas: Nueva Sociedad, 1998.

. "Uruguay: el presidencialismo pluralista". Revista Mexicana de Sociología, 2, 1998.

La segunda transición en el Uruguay. Gobierno y partidos en un tiempo de reformas. Montevideo: Fundación de Cultura Universitaria, 2000a.

Autoridad presidencial y relaciones de partido en el gobierno de Jorge Batlle. En: ICP Elecciones 1999-2000. Montevideo: EBO, 2000b.

(Ed.). Tipos de presidencialismo y coaliciones políticas en América Latina. Buenos Aires: CLACSO, 2001.

"Democracia pluralista y estructura política del Estado". Revista Uruguaya de Ciencia Política, 14, $2004 a$.

La reforma educativa en el Uruguay (1995-2000): virtudes y problemas de una iniciativa heterodoxa. CEPAL . Serie Políticas Sociales 91. Santiago de Chile, 2004b.

. La izquierda uruguaya entre la oposición y el gobierno. Montevideo: Fin de Siglo, 2004c.

_. Uruguay: Reformas políticas en la nueva etapa democrática. In: ZovatTo, D.; ORozco, J. (eds.). Reforma política y electoral en América Latina. México: IDEA-Instituto de Investigaciones Jurídicas, UNAM, 2007b.

Uruguayan Parties: Transition within Transition. In: LAWSON, K.; MerKL, P. (eds.). When Political Parties Prosper. Boulder: Lynne Rienner Publishers, 2007c.

"La social democracia criolla". Nueva Sociedad, 217, 2008.

Uruguay: A Social Democratic Government in Latin America. In: LEVITSKY, S.; ROBERTS, K. (eds.). The Resurgence of the Latin American Left. Baltimore: The Johns Hopkins University Press, $2011 \mathrm{a}$.

"Social Democracy in the Global South. Brazil, Chile and Uruguay in a Comparative Perspective". Social Europe Journal, vol.6, $\mathrm{n}^{\circ} 1,2011 \mathrm{~b}$.

; ARMAS, A. Uruguay: Clases medias y procesos electorales en una democracia de partidos. En: PARAmIO, L. (ed.). Clases Medias y Procesos Electorales en América Latina. Madrid: Editorial Pablo Iglesias, 2012.

; LUNA, J. P. "Uruguay: Las claves de crecimiento del Frente Amplio", Ponencia presentada al Seminario "Democracia y Opinión Pública en América Latina". Latinobarómetro-Clacso, Buenos Aires, 2002. 
LaPalombara, J. Democracy Italian Style. New Haven: Yale University Press, 1987.

Lawson, K. \& Lanzaro, J. (eds.). Political Parties and Democracy. Santa Barbara: Praeger, 2010.

LIJPHART, A. "Consociational Democracy". World Politics, 1969.

LINDBLOM, C. "The Science of Muddling Trough". Public Administration Review, 39, 1959.

1965

The Intelligence of Democracy: Decision Making Through Mutual Adjustment. New York: The Free Press,

LIPSET, S. M. "Radicalism or Reformism: The Sources of Working Class Politics". American Political Science Review, $77,1,1983$

; RokKan, S. Party Systems and Voter Alignments. New York: Free Press, 1967.

LORA, E. Las reformas estructurales en América Latina: qué se ha reformado y cómo medirlo. BID DT 462. Washington DC. Versión actualizada 2012: BID WP 346, 2001.

LUNA, J. P. "Frente Amplio and the Crafting of a Social Democratic Alternative in Uruguay". Latin American Politics and Society, 49-4, 2007.

MAIR, P. Party System Change. New York: Oxford University Press, 1997.

Manin, B. The Principles of Representative Government. New York: Cambridge University Press, 1997.

MannheIM, K. Man and Society. London: Routledge \& Kegan Paul, 1940.

Maravall, J. M. "What is Left? Social Democratic Policies in Southern Europe". Fundación Juan March, Working Paper 36, Madrid, 1992

Marshall, T. H. Class, Citizenship and Social Development. New York: Doubleday, 1964.

MedinA, A. D. El voto que el alma pronuncia. Montevideo: FCU, 1994

MerkeL, W. ¿Final de la Socialdemocracia? Valencia: Edicions Alfons el Magnànim, 1995.

; Petring, A. "La social democracia en Europa. Un análisis de su capacidad de reforma". Nueva Sociedad, 217. Buenos Aires, 2008

Mesa-Lago, C.; Bertranau, F. Manual de Economía de la Seguridad Social. Montevideo: CLAeH, 1998.

Mieres, P. "Cambios en el sistema de partidos uruguayo". Cuadernos del CLAEH, 62, 1992.

Miliband, R. Parliamentary Socialism. A Study in the Politics of Labour. London: Merlin Press, 1972.

Moore, B. Social Origins of Dictatorship and Democracy. Boston: Beacon, 1966.

PÉREZ, R. "Los partidos en el Uruguay moderno". Cuadernos del CLAEH, n 31, 1984

. "Cuatro antagonismos sucesivos. La concreta instauración de la democracia uruguaya". Revista Uruguaya de Ciencia Política, 2, 1988.

Przeworski, A. \& Sprague, J. Paper Stones. A History of Electoral Socialism. Chicago: The University of Chicago Press, 1986.

Przeworski, A. How Many Ways Can Be Third? In: GLYN, A. (ed.). Social Democracy in Neoliberal Times. The Left and Economic Policy since 1980. New York: Oxford University Press, 2001.

RIBEIRO, D. As Américas e a Civilização. São Paulo: Companhia das Letras. Nueva edición de la obra publicada por CEAL: Buenos Aires, 2007 [1969].

Roberts, K. “¿Es posible una social democracia en América Latina?”. Nueva Sociedad, 217, 2008.

RoberTson, D. A Theory of Party Competition. London: Wiley, 1976.

SARTORI, G. Partidos y Sistemas de Partidos. Madrid: Alianza, 1980 


\section{LANZARO, J. Continuidad y cambios en una vieja democracia de partidos..}

Ingeniería Constitucional Comparada. México: FCE, 1994.

SChmITter, P. "Still the Century of Corporatism". The Review of Politics, XXXVI, 1974.

Scoppola, P. La repubblica dei partiti: profilo storico della democracia. In: Italia (1945-1990). Bologna: II Mulino, 1991.

SIAVELIS, P. "Elite-Mass Congruence, Partidocracia and the Quality of Chilean Demcoracy". Journal of Politics in Latin America, 3, 2009.

Sotelo, M. "La longevidad de los partidos tradicionales uruguayos". En: Los partidos políticos uruguayos en tiempos de cambios. Montevideo: Universidad Católica, 1999.

SChatTSChneider, E. Party Government. New York: Holy, Rinehart \& Winston, 1942.

Stokes, S. "Political Parties and Democracy". American Review of Political Science, 2, 1999.

TRUman, D. The Governmental Process. New York: Knopf, 1951.

URBINATI, N. "O que torna a representação democrática?". Lua Nova, 67, 2006.

VANGER, M. José Batlle y Ordóñez of Uruguay: The Creator of his Times 1902-1907. Harvard University Press, 1963. En español: José Bat/le y Ordóñez: el creador de su tiempo. Montevideo: Ediciones de la Banda Oriental, 1992.

El país modelo. Montevideo: Arca-Ebo, 1983.

Weyland, K.; Madrid, R.; Hunter, W. (eds.). Leftist Governments in Latin America. New York: Cambridge University Press, 2010.

Jorge Lanzaro - jorge.lanzaro@gmail.com

Submetido à publicação em agosto de 2012.

Aprovado para publicação em abril de 2013. 